\title{
Precautionary Management and the Development of Future Fishing Opportunities: The International Regulation of New and Exploratory Fisheries
}

\author{
Richard Caddell
}

Senior Research Associate and Nippon Foundation Senior Nereus

Fellow, Netherlands Institute for the Law of the Sea, Utrecht University,

The Netherlands; Lecturer in Law, Cardiff University, United Kingdom

j.r.caddell@uu.nl

\begin{abstract}
The extensive pressures upon current commercial fisheries, compounded by the projected impacts of climate change and associated processes on marine ecosystems, will increasingly displace elements of future fishing effort towards new locations, target species and techniques. For transboundary stocks, where a new or exploratory fishery is contemplated, Article 6(6) of the UN Fish Stocks Agreement 1995 mandates cautious conservation measures to acquire sufficient catch data to assess the impacts of fishing on the stock and surrounding ecosystem. Thereafter, if appropriate, measures may be adopted to facilitate the gradual development of the fishery and its eventual transition to commercial management. However, there has been minimal analysis of the regulatory requirements for emergent fisheries during this interim stage. This article accordingly collates and evaluates the current international law and practice towards new and exploratory fisheries, with particular reference to Antarctic developments and the protection of vulnerable marine ecosystems from proliferating deep-sea fisheries.
\end{abstract}

* This research was funded and conducted under the Nereus Program of the Nippon Foundation (www.nereusprogram.org). The author thanks Alex Oude Elferink and Erik J. Molenaar (NILOS) and an anonymous reviewer for their extremely helpful comments, as well as participants in workshops at the K.G. Jebsen Centre for the Law of the Sea, UiT The Arctic University of Norway, Tromsø, and the Fisheries Centre, University of British Columbia, and delegates at the resumed Review Conference of the Un Fish Stocks Agreement, at which earlier versions of this work were presented; the usual caveats apply. Particular thanks are due to Sasha Caddell for her exceptional support throughout this extensive project.

(C) RICHARD CADDELL, 2017 | DOI 10.1163/15718085-13310013

This is an open access article distributed under the terms of the prevailing CC-BY-NC license at the time of publication. 


\section{Keywords}

new fisheries - exploratory fisheries - precautionary approach - UN Fish Stocks Agreement 1995 - Commission for the Conservation of Antarctic Marine Living Resources (CCAMLR) - vulnerable marine ecosystems

\section{Introduction}

It is increasingly evident that significant adjustments to existing marine capture fisheries will be necessary in order to meet the future demand for seafood from an ever-expanding global population. Concerns have long been raised that many commercial fisheries have consistently operated at or beyond their maximum sustainable yield, imperilling their long-term ecological and economic sustainability. Indeed, the United Nations Food and Agriculture Organization (FAO) considers that, even accounting for regional variations and fluctuations, over thirty percent of global fish stocks are at present overfished, and approximately sixty percent are deemed to be fully fished. ${ }^{1}$ With states having generally proven unwilling to countenance sweeping reductions to allocations, there is accordingly a pressing need to consider other options, including the extension of current effort into different locations and depths, deploying novel or adapted fishing techniques and gear, and targeting new or previously under-fished species.

In parallel to these considerations, climate change and associated processes are also poised to play a key role in the (re-)distribution of fish stocks in the coming decades and, by extension, the location and composition of future capture fisheries. Rising sea temperatures and ocean acidification will continue to exert a strong influence over the future distribution patterns of fish and interdependent species, with many commercially valuable stocks now 'undergoing phenological and geographical shifts as a result of warming. ${ }^{2}$ Current projections indicate a general trend towards the eventual displacement of numerous

1 FAO, The State of World Fisheries and Aquaculture 2016: Contributing to Food Security and Nutrition for All (FAO, Rome, 2016) at p. 38.

2 J-P Gattuso, A Magnan, R. Billé, WWL Cheung, EL Howes, F Joos, D Allemand, L Bopp, SR Cooley, CM Eakin, O Hoegh-Guldberg, RP Kelly, H-O Pörtner, AD Rogers, JM Baxter, D Laffoley, D Osborn, A Rankovic, J Rochette, UR Sumaila, S Treyer and C Turley, 'Contrasting Futures for Ocean and Society from Different Anthropogenic $\mathrm{CO}_{2}$ Emissions Scenarios' (2015) 349 Science $4722-4732$, at p. 4732 . 
fish species to deeper ocean waters and the Polar Regions, ${ }^{3}$ with a corresponding reduction in catch potential in the Tropics. ${ }^{4}$ Indeed, warm-water species have increasingly dominated global catches in recent years, ${ }^{5}$ which has been primarily attributed to a tangible shift in ocean temperatures. ${ }^{6}$ Similar patterns of adjustment are also becoming apparent on a regional basis. In Europe, for instance, warming seas have seemingly provoked distributional shifts in a number of pelagic fish species endemic to the region, ${ }^{7}$ while irregular temperature 'spikes' have created conditions conducive to the greater availability of particular stocks in individual fishing seasons. ${ }^{8}$ The dispersal of stocks to new depths and locations accordingly presents inviting commercial possibilities for particular coastal states, albeit at the likely expense of others. Indeed, recent evidence suggests that warm-water species have now become present in British and Irish waters in sufficient quantities to generate new and lucrative fishing opportunities for species such as sea bass, red mullet, John Dory, anchovy and squid. ${ }^{9}$ Future prospects for new commercial fisheries have also been tentatively raised in the High North, as warming seas are predicted to gradually facilitate the removal of natural climatic barriers to the colonisation of Arctic waters by a number of species across the coming decades. ${ }^{10}$

AL Perry, PJ Low, JR Ellis and JD Reynolds, 'Climate Change and Distribution Shifts in Marine Fishes' (2005) 308 Science 1912-1915, at pp. 1913-1914.

WWL Cheung, VWY Lam, JL Sarmiento, K Kearney, R Watson, D Zeller and D Pauly, 'Large-Scale Redistribution of Maximum Fisheries Catch Potential in the Global Ocean under Climate Change' (2010) 16(1) Global Change Biology 24-35, at pp. 30-31.

$5 \quad$ UR Sumaila, WWL Cheung, VWY Lam, D Pauly and S Herrick, 'Climate Change Impacts on the Biophysics and Economics of World Fisheries' (2011) 1 Nature Climate Change 449456 , at p. 451.

WWL Cheung, R Watson and D Pauly, 'Signature of Ocean Warming in Global Fisheries Catch' (2013) 497 Nature 365-368, at pp. 365-66.

I Montero-Serra, M Edwards and MJ Genner, 'Warming Shelf Seas Drive the Subtropicalization of European Pelagic Fish Communities' (2015) 21(1) Global Change Biology 144-153, at pp. 149-150.

8 P Petitgas, J Alheit, MA Peck, K Raab, X Irigoien, M Huret, J Van Der Kooij, T Pohlmann, C Wagner, I Zarraonaindia and M Dickey-Collas, 'Anchovy Population Expansion in the North Sea' (2012) 444 Marine Ecology Progress Series 1-13, at p. 10.

9 See WWL Cheung, J Pinnegar, G Merino, MC Jones and M Barange, 'Review of Climate Change Impacts on Marine Fisheries in the UK and Ireland' (2012) 22(3) Aquatic Conservation: Marine and Freshwater Ecosystems 368-388, at p. 374.

10 See further MS Wisz, O Broennimann, P Grønkjær, PR Møller, SM Olsen, D Swingedouw, RB Hedeholm, EE Neilsen, A Guisan and L Pellissier, 'Arctic Warming Will Promote Atlantic-Pacific Fish Interchange' (2015) 5 Nature Climate Change 261-265, at p. 262 and JS Christiansen, CW Mecklenburg and OV Karamushko, 'Arctic Marine Fishes and their 
The pursuit of prospective fishing opportunities nevertheless presents considerable attendant management challenges. Emerging fisheries are acutely susceptible to the risks of over-exploitation, where the combination of an effective regulatory vacuum and the prospect of high short-term profits has served to facilitate a bleakly familiar cycle of 'boom-and-bust'. Moreover, new fisheries are often pursued in locations for which there is limited scientific knowledge of the stock and its surrounding ecosystem; hence there is significant uncertainty as to the impacts of fishing upon both the target species and the wider marine environment. The regulation of new and exploratory fisheries accordingly represents an intriguing and challenging context by which to consider the practical application of the precautionary approach to international fisheries management.

Despite these increasingly pressing concerns, the legal requirements incumbent in the initiation of new fishing opportunities have thus far received surprisingly little analysis. As outlined below, where 'new or exploratory fisheries' are under contemplation, Article 6(6) of the 1995 UN Fish Stocks Agreement $(\mathrm{UNFSA})^{11}$ prescribes a broad obligation to adopt cautious conservation and management measures at a preliminary stage, which are to remain in effect until sufficient data are available to permit a clear assessment of the impact of fishing upon the long-term sustainability of the target stock and the wider ecosystem. Thereafter, if feasible and appropriate, further conservation and management measures may be implemented, with a view towards the gradual development of the fishery.

Although these requirements have been framed in the specific context of straddling and highly migratory fish stocks, similar policies and commitments have been adopted by a growing number of regulatory bodies in recent years. While little explored, such provisions collectively represent a key element of the precautionary approach to fisheries management and envisage markedly stronger controls over new and exploratory activities than are applied to existing capture fisheries, given the general lack of baseline data concerning the

Fisheries in the Light of Global Change' (2014) 20(2) Global Change Biology 352-359, at pp. 354-356. The extent of this potential windfall is nevertheless highly uncertain, as projections conversely indicate that ocean acidification and fresh-water inflow into this region may ultimately inhibit particular fisheries: see VWY Lam, WWL Cheung and UR Sumaila, 'Marine Capture Fisheries in the Arctic: Winners or Losers under Climate Change and Ocean Acidification?' (2016) 17(2) Fish and Fisheries 335-357, at pp. 348-349.

11 Agreement for the Implementation of the Provisions of the United Nations Convention on the Law of the Sea of 10 December 1982 Relating to the Conservation and Management of Straddling Fish Stocks and Highly Migratory Fish Stocks (New York, 4 August 1995, in force 11 December 2001) 2167 UNTS 88. 
sensitivity of the target stock and its associated ecosystem to the impacts of future fishing.

A degree of mystery surrounds the scope and application of these requirements, however. Interpretive questions arise as to the definitional parameters of both 'new' and 'exploratory' fisheries and the precautionary management regime required throughout these preliminary stages of a nascent fishery. The threshold requirements incumbent in the transition of new and exploratory fisheries to full management are also obscure and, to date, the practice of states and regional fisheries management organisations (RFMOs) in implementing these commitments has been subject to minimal investigation. This article accordingly evaluates the range of legal obligations engaged by the pursuit of new and exploratory fisheries and collates the developing international practice concerning the regulation of such activities.

To this end, this article first considers the regulatory challenges raised by new and exploratory fisheries and provides an overview of the current international legal framework addressing such activities. Thereafter, as this article outlines, the regulation of new and exploratory fisheries can be seen to have emerged in two distinct contexts. In the first instance, the need to address the supervisory lacunae raised by the unregulated development of new fishing activities was first recognised by the Commission for the Conservation of Antarctic Marine Living Resources (CCAMLR). The nascent policies elaborated under these auspices influenced the concurrent negotiation of the UNFSA, resulting in the incorporation of specific requirements for new and exploratory fisheries within the general framework for the precautionary approach to fisheries management. In turn, the UNFSA has directly influenced the mandates of subsequent RFMOS so as to facilitate the regulation of new and exploratory fisheries as a standard feature of the practice of the more recently inaugurated fisheries bodies. A degree of 'retro-fitting' of similar requirements has also been considered within pre-existing institutions, as new and exploratory fisheries have steadily emerged in other regions. This analysis of the law and practice pertaining to new and exploratory fisheries will demonstrate that a clear framework has been established for the further interpretation of Article 6(6) of the UNFSA to manage such activities in a precautionary and environmentally sensitive manner, although practical difficulties have been encountered in securing sufficient data and in facilitating an appropriate transition point to full commercial management.

The second - and more recently evident - factor underpinning the oversight of new and exploratory fisheries has been an increased international focus upon ensuring responsible fisheries in the marine ecosystem, as mandated by the UN General Assembly (UNGA) in a series of influential Resolutions 
adopted since 2004. Particular concerns have been raised by the UNGA over the impacts of under-regulated deep-sea bottom-fishing upon the benthic environment, with RFMOs having been primarily charged with implementing standards to protect vulnerable marine ecosystems (VMEs) from the adverse consequences of an emerging trend towards fishing in deeper waters. In this respect, exploratory bottom fishing has been subject to an increased volume of regulation by RFMOs in this specific context, based on these political imperatives and drawing upon the technical advice of the FAO. This has generated a strong degree of uniformity in these requirements within a relatively short time-frame, which may be accordingly considered to represent the minimum standards for exploratory fishing activities in the deep-sea environment and a key component of the current global regime for the protection of vMEs.

\section{The Objective and Conduct of New and Exploratory Fisheries}

The requirements of new and exploratory fishing activities have generally occupied a peripheral position within the otherwise extensive legal framework for the regulation of fisheries. There is as yet no universal definition of either a 'new' or an 'exploratory' fishery in current international law: indeed, these terms were left undefined in the UNFSA while, as discussed below, individual RFMOs have adopted subtly different approaches to address the particular conditions and circumstances through which new and exploratory fisheries are conducted under their regulatory purviews. Likewise, in some circumstances these specific activities have become steadily blurred with other types of non-commercial fishing, rendering the distinction between exploratory and research fisheries increasingly fluid. Accordingly, the policies towards new and exploratory fisheries by various actors and institutions have largely developed in a piecemeal and $a d$ hoc fashion.

The nature of fishing activities in particular regions also means that the oversight of new and exploratory fisheries as a general concern is far from an equal regulatory priority for all RFMOs, further compounding a sense of managerial fragmentation. There are isolated examples of extensive practice towards new and exploratory fisheries in particular regions, notably the Southern Ocean. For many other actors, such policies remain at a preliminary stage, as the regulation of these activities has become a more recent concern, prompted largely by global initiatives towards the concerted protection of VMEs, as discussed further below. Meanwhile, other RFMOs have not substantively considered this issue at all. These regulatory conditions have thereby militated somewhat against the emergence of a clear and consistent definition of, and cross-cutting 
rules for, the further oversight of new and exploratory fisheries on a global basis. Nevertheless, as this article reveals, regional innovations - notably within Antarctic fisheries - can be seen to have pioneered a series of guiding principles by which to regulate new and exploratory fisheries. The coalescence of these policies, initially developed to bring procedural order to specific emerging fishing opportunities, has in the absence of clearer global rules, generated regional practices that retain a strong emphasis on precautionary management, prior approval, extensive data collection and ongoing scientific review.

New and exploratory fishing activities are primarily exemplified in three broad contexts. In the first instance, fisheries may be tentatively introduced in respect of species that have not previously been fished on a commercial basis. Second, new fishing areas may be piloted under the auspices of extant regulatory structures for species that may already be subject to exploitation. Third, new methods may be developed to catch species within an existing fishery, such as the use of new techniques or equipment, or by adjusting catch effort at a point higher or lower in the water column. Each of these scenarios will inevitably involve a strong degree of uncertainty over the prospective impacts of even a limited degree of fishing activity. The regulatory challenge incumbent in new and exploratory fisheries is therefore to ensure that these activities shall not compromise the stock in question, or its associated ecosystem, before meaningful and prudent regulation can be applied to it. Indeed, such a fate has befallen previously unfished stocks with alarming regularity, and considerable anxiety has already been voiced over the environmental vulnerability of prospective fisheries generated by changing ocean dynamics. ${ }^{12}$

New and exploratory fisheries remain fundamentally distinct to established fisheries. They are primarily characterised by a lack of scientific data concerning stock levels and the surrounding ecosystem, which militates against the application of commercial catch limits. Such fishing is instead subject to a (pre-)cautious approach to regulation, advancing considerably more stringent controls on access and effort than are generally imposed under more established management conditions, which may be gradually relaxed as additional data are subsequently generated. The effective regulation of new and exploratory fisheries therefore places considerable importance upon the collection of particular data, because such activities are often pursued in locations for which there is little scope to acquire fisheries-independent information on the target stock and its accompanying environment. The endorsement of a pilot fishing programme accordingly represents a calculated regulatory gamble that a restricted degree of supervised fishing will yield sufficient data to allow for

Wisz et al. (n 10) at p. 263 . 
increasingly accurate projections of the commercial feasibility of that fishery, as well as its prospective impact upon the wider marine ecosystem, while inflicting minimal environmental damage in the process. Indeed, the regulatory conundrum posed by new and exploratory fisheries was succinctly articulated by the FAO at the negotiating sessions for the UNFSA:

It is usually impossible to forecast, with any degree of accuracy, the impact that a new fishery will have before it starts and some data are collected. It might therefore be imagined that no fishery could be developed because evidence of the absence of adverse impact cannot be given by those involved in the venture. A precautionary approach, in such a case, should lead to agreement for a pilot fishery large enough to collect data and build up the scientific evidence required, but small enough to ensure that no irreversible effect is likely. In practice, there will usually be a trade-off: a small amount of risk for the resources being exploited will have to be accepted in exchange for the possibility to provide food and a livelihood for humans. ${ }^{13}$

It is difficult to accurately quantify the scale of new and exploratory fisheries on a global basis. By its very nature, such fishing is highly variable and the exploitation of intended pilot fisheries may in practice be influenced as much by commercial, meteorological and environmental factors as by regulatory considerations in any given fishing season. At present, new and exploratory fisheries are most prevalent in the Southern Ocean, where such endeavours have been regulated under the umbrella of CCAMLR for over twenty-five years. New and exploratory fisheries have consistently expanded in these waters since 2000, with similar arrangements tentatively developing within other regions in recent years. An increasing degree of exploratory deep-sea fishing has also been conducted in other locations, particularly the North Atlantic, for which a distinct regulatory regime has begun to emerge, guided primarily by the political spur provided by adherence to pertinent UNGA Resolutions.

Despite the logistical, practical and financial challenges incumbent in such activities, the development of new and exploratory fisheries has steadily become an issue of increasing regulatory significance for a number of RFMOs.

13 FAO, The Precautionary Approach to Fisheries with Reference to Straddling Fish Stocks and Highly Migratory Fish Stocks; Document A/CONF.164/INF/8, 26 January 2994, para 90; reproduced in J-P Lévy and GG Schram (eds), United Nations Conference on Straddling Fish Stocks and Highly Migratory Fish Stocks: Selected Documents (Martinus Nijhoff, The Hague, 1996) at p. 574 . 
Indeed, new and exploratory fisheries may represent the only potential fishing opportunities available in principle to purported new entrants to particular regional bodies, as has for instance been clearly stated in the context of the North Atlantic region..$^{14}$ It is therefore likely that new and exploratory fisheries will continue to expand in the future as existing constituents strive to maximise yields from these allocations, while new participants seek to secure access to stocks in a climate of increasing protectionism within current regulatory structures..$^{15}$

\section{The Global Regulation of New and Exploratory Fisheries}

The first formal recognition of the need to regulate new and exploratory fisheries on a multilateral basis can be traced back to 1989, under the auspices of CCAMLR. ${ }^{16}$ These emerging policies within CCAMLR exerted a clear influence over the elaboration of a specific provision addressing new and exploratory fisheries within the UNFSA, which was negotiated at a broadly similar time.

14 Indeed, both the Northwest Atlantic Fisheries Organization (NAFO) and the North-East Atlantic Fisheries Commission (NEAFC) have advised prospective new participants that, 'presently and for the foreseeable future', their respective stocks have been 'fully allocated' with fishing opportunities for new members therefore likely to be restricted to new fisheries: see NAFO Resolution 1/99 of 17 September 1999 to Guide the Expectations of Future New Members with Regard to Fishing Opportunities in the NAFo Regulatory Area and the parallel Guidelines for the Expectation of Future New Contracting Parties with Regard to Fishing Opportunities in the NEAFC Regulatory Area, adopted at the Twenty-Second Annual Meeting of NEAFC in 2003.

15 Whereas Article 8(3) of the UNFSA provides that any state demonstrating a 'real interest' in a particular fishery is eligible for membership of any subsequent RFMO regulating these stocks, fishing opportunities for new entrants to a number of bodies have proved to be rather more ephemeral in reality: A Serdy, 'Postmodern International Fisheries Law, Or We Are All Coastal States Now' (2011) 6o(2) International and Comparative Law Quarterly $387-422$, at pp. 398-418. In practice, however, this trend appears likely to continue in respect of new and exploratory fisheries within particular RFMOs; notwithstanding the references to new fisheries, NEAFC and NAFO have consistently exercised exclusionary practices towards purported new entrants: A Serdy, The New Entrants Problem in International Fisheries Law (Cambridge University Press, Cambridge, 2016) at pp. 96-100. Tellingly, the NEAFC position on exploratory bottom fisheries remains contingent upon the prior approval of its Members: Recommendation 9:2015, Consolidated Text of all NEAFC Recommendations on Regulating Bottom Fishing, available online at www.neafc .org, Article 7(4); see further $n 195$ et seq.

16 Report of the Eighth Meeting of the Commission (CCAMLR-VIII), para. 123. 
Moreover, the UNFSA has in turn inspired a varying degree of recognition of new and exploratory fisheries within the constituent treaties of subsequent RFMOs. Beyond the UNFSA, however, there are few references to new and exploratory fisheries at the global level, although these activities have received further attention during the past decade within the UNGA, which has sought to mitigate the impacts of deep-sea fishing - including exploratory activities upon VMES.

The regulation of new fishing opportunities was not expressly addressed at the Third United Nations Conference on the Law of the Sea (UNCLOS III) negotiations, from which the UN Convention on the Law of the Sea 1982 (LOSC) $)^{17}$ and its general framework for fisheries competences would ultimately emerge. Under the LOsc, states enjoy extensive rights to utilise fisheries resources on the high seas ${ }^{18}$ and in their respective exclusive economic zones (EEZs), ${ }^{19}$ subject to broad obligations concerning the conservation of the stocks in question. ${ }^{20}$ Although the LOSC is silent on new and exploratory fisheries per se, it is nonetheless implicit in these arrangements that fishing, whether industrial or research-oriented, should not be conducted in a manner that compromises the rights of other states or the health of the target stock and its wider ecosystem. To this end, Article 61 requires coastal states to take into account the interdependence of stocks and prospective impacts upon associated or dependent species in framing arrangements for fishing in the EEz. Moreover, the significant data-collection obligations incumbent in new and exploratory fisheries complement the requirements of Article 61(2) for a coastal state to take into account 'the best scientific evidence available to it' to ensure that marine living resources are not endangered by over-exploitation. Parallel arrangements for the high seas are more circumspect, with states under the more nebulous obligation to exercise 'due regard' towards the interests of others. ${ }^{21}$

These provisions are neither expressly nor implicitly restricted to preexisting fishing activities, however. They have been drafted in an inclusive manner, with the intention of promoting informed decision-making founded upon access to all pertinent data; hence there would appear to be little practical merit in a narrow interpretation that would exempt new and exploratory fisheries from these requirements. Indeed, the governance regime envisaged by

17 United Nations Convention on the Law of the Sea (Montego Bay, 10 December 1982, in force 16 November 1994) 1883 UNTS 396.

18 Articles $87(1)$ (a) and 116.

19 Article 62.

$20 \quad$ Articles 61 (EEZ) and 117-119 (high seas).

21 Article $87(2)$. 
the LOSC is expressly founded upon securing the maximum sustainable yield of fish resources, for which the pursuit of new and exploratory fisheries legitimately represents an important stage in meeting this objective. Accordingly, it is tenable to assert that the impacts of pilot fishing activities ought to be considered within the broad ambit of these requirements.

Thus far, however, there has been little consideration of the application of these provisions in the specific context of future fishing opportunities. The unilateral initiation of experimental fishing activities was challenged in the Southern Bluefin Tuna Cases, ${ }^{22}$ in which high seas entitlements were invoked to curtail catches that were potentially unsustainable and allegedly represented a circumvention of national catch restrictions. ${ }^{23}$ Although not an exact template of the usual pursuit of new and exploratory fishing opportunities, the International Tribunal for the Law of the Sea (ITLOS) indicated that obligations to act 'with prudence and caution' and to cooperate effectively with other participants in the fishery constitute key considerations for the pursuit of experimental fishing programmes. ${ }^{24}$ This position also appears implicit within the LOSC, which prescribes further obligations to exchange data on catch and fishing effort in respect of both the $\mathrm{EEZ}^{25}$ and the high seas. ${ }^{26}$ Ultimately, as the RFMO practices outlined below attest, data-sharing and prior notification have become the general hallmarks of current regulatory mechanisms concerned with new and exploratory fisheries, and are thus broadly reflective of the spirit of the Losc regime.

The general framework for fisheries governance advanced under the LOSC has been further developed through the UNFSA, which has expressly adopted a regulatory position on new and exploratory fisheries. To this end, Article 6(6) provides:

For new and exploratory fisheries, States shall adopt as soon as possible cautious conservation and management measures, including, inter alia, catch limits and effort limits. Such measures shall remain in force until there are sufficient data to allow assessment of the impact of the fisheries

Southern Bluefin Tuna (New Zealand v. Japan; Australia v. Japan), Provisional Measures, Order of 27 August 1999, ITLOS Reports 1999.

Ibid., para 9o(d).

Ibid., paras $77-78$. The resulting Arbitral Tribunal subsequently ruled that it did not in fact have competence over the dispute and discharged the order for provisional measures previously made by ITLOS.

Article 61(5).

Article 119(2). 
on the long-term sustainability of the stocks, whereupon conservation and management measures based on that assessment shall be implemented. The latter measures shall, if appropriate, allow for the gradual development of the fisheries.

Article 6(6) is therefore of clear significance in consolidating regulatory responses to the particular challenges posed by new and exploratory fisheries. Indeed, it represents the first formal recognition of new and exploratory fisheries within an instrument of global application, ${ }^{27}$ thereby elevating this issue beyond a matter of specific regional concern. Moreover, as intended, the UNFSA has exerted considerable influence over the drafting of the constituent treaties of subsequent RFMOs, a number of which (as outlined below) have accordingly enshrined the oversight of new and exploratory fisheries within their regulatory purviews, a development that might not have otherwise occurred as readily as has subsequently transpired.

Equally notable is the positioning of these requirements within Article 6 of the UNFSA, a provision that articulates the intended application of the precautionary approach to fisheries management and was considered revolutionary at the time. ${ }^{28}$ In this manner, the UNFSA reinforces a dichotomy that making provision for the regulation of new and exploratory fisheries constitutes a core component of the application of the precautionary approach to fisheries management, and that such activities should in turn proceed in a graduated, monitored and precautionary manner.

This symbolism notwithstanding, taken on its own terms Article 6(6) has arguably been of limited practical utility in framing specific regulatory responses to new and exploratory fisheries. Ratione materiae, these requirements are confined to the particular context of straddling and highly migratory fish stocks. Likewise, despite the stated expansion of the scope of Articles 6 and 7 to encompass 'areas under national jurisdiction', ${ }^{29}$ later practices and analyses have cast doubt as to whether this term is as clear-cut as it initially appears and

27 Article 6(6) is also reproduced largely verbatim as Article 7.5.4 of the FAO Code of Conduct for Responsible Fisheries, albeit using the term 'should', where the UnFSA decrees 'shall'.

28 See especially PGG Davies and C Redgwell, "The International Legal Regulation of Straddling Fish Stocks' (1997) 67 British Yearbook of International Law 199-274, at pp. 259265; F Orrego Vicuña, The Changing International Law of High Seas Fisheries (Cambridge University Press, Cambridge, 1999) at p. 162; D Freestone, 'Implementing Precaution Cautiously: The Precautionary Approach in the Straddling and Highly Migratory Fish Stocks Agreement' in E Hey (ed.), Developments in International Fisheries Law (Kluwer, Alphen aan den Rijn, 1999) 287-325.

Article 3(1). 
suggest that it may be restricted solely to fisheries within the EEz. ${ }^{30}$ Moreover, beyond a broad commitment to precautionary oversight and ensuring that the commercialisation of a new or exploratory fishery proceeds on a gradual basis, the UNFSA offers little indication as to the definitional thresholds of these terms or how this process is intended to operate in practice. This is perhaps unsurprising, given that Article 6(6) is essentially reflective of contemporaneous developments within CCAMLR, which had not fully elaborated its regulatory model for new and exploratory fisheries by the time at which the UNFSA was concluded. Instead, the maturation of policies towards new and exploratory fisheries occurred exclusively within CCAMLR during the period between the drafting of the UNFSA and its formal entry into force in 2001, a process over which Article 6(6) ultimately exercised a negligible influence.

The guiding role of CCAMLR in the elaboration of Article 6(6) is clearly illustrated by the submission of a draft convention prior to the conclusion of the initial negotiating text, ${ }^{31}$ which appears to have been the only procedural model for new and exploratory fisheries to have been tabled at the Fish Stocks Conference, and whose proponents were, with the exception of Iceland, CCAMLR Members at the material time and actively engaged in the process of developing regulatory guidance for pilot fisheries. With regard to 'newly discovered' stocks, it was suggested that in order to provide for effective scientific review and assessment and to avoid delays in establishing effective control over such fisheries, the coastal states 'in whose exclusive economic zone the stock occurs' ought to assume management authority for an undefined 'initial interim period', following which responsibility would be vested in the relevant RFMO (or by agreement in the absence of such a body). Thereafter, measures should be established to allow for the gradual development of the fishery, alongside the introduction of precautionary management thresholds and bycatch limits. ${ }^{32}$ Nevertheless, beyond a broad obligation for states to enter into

$30 \quad$ M Tsamenyi and Q Hanich, 'Fisheries Jurisdiction under the Law of the Sea Convention: Rights and Obligations in Maritime Zones under the Sovereignty of Coastal States' (2012) 27(4) International Journal of Marine and Coastal Law 783-793, at pp. 790-791.

31 Draft Convention submitted by Argentina, Canada, Chile, Iceland and New Zealand; Document A/CONF.164.L.11/Rev.1; reproduced in Lévy and Schram (n 13) at p. 176.

32 Ibid. This reference to the EEz may be further suggestive of an intent to exclude areas under sovereignty from the scope of Article 3(1). The Draft Convention further specified that '[e]arly large-scale fisheries on newly discovered stocks shall be prohibited', implying an emphasis upon restraint in the pursuit of new marine resources that has since been the general hallmark of CCAMLR in this respect, although the notion of a large-scale fishery was also left undefined in this formulation. 
consultations with respect to new fisheries, ${ }^{33}$ no specific procedures were stipulated within the UNFSA and the formulation of these requirements appears to have been essentially deferred to the individual RFMO in question.

Likewise, a us proposal for new and exploratory fisheries to be conducted pursuant to a specific data collection programme - which mirrored its voluntary practices within CCAMLR at the material time ${ }^{34}$ - also failed to graduate into the final version of the UNFSA, ${ }^{35}$ although in practice those RFMOs that have developed a clear policy on such fishing have subsequently insisted upon adherence to this procedure. Ultimately, given this drafting history, the regulatory intent of Article 6(6) is more appropriately interpreted by collating the extensive guiding practice of CCAMLR towards new and exploratory fisheries, a task to which this article now turns.

\section{New and Exploratory Fisheries in Antarctic Waters: The Development of the CCAMLR Regime}

The CCAMLR regime is a central element of the Antarctic Treaty System (ATS), under which the Convention for the Conservation of Antarctic Marine Living Resources ${ }^{36}$ was concluded in 1980 and entered into force in 1982 . The CAM LR Convention provided for the establishment of a management body, in the form of CCAMLR,${ }^{37}$ which is supported by a Scientific Committee and its associated advisory fora, which act as consultative bodies to the Commission. ${ }^{38}$ The primary aim of the CAMLR Convention is articulated in Article II as being 'the conservation of Antarctic marine living resources', 39 defined as 'the populations

\footnotetext{
33 Article 8(2).

34 See $\mathrm{n} 98$ et seq.

35 GJ Hewison, 'The Precautionary Approach to Fisheries Management: An Environmental Perspective' (1996) 11(3) International Journal of Marine and Coastal Law 301-332, at p. 323.

36 Convention for the Conservation of Antarctic Marine Living Resources (Canberra, 20 May 1980, in force 7 April 1982) 1329 UNTS 47 ('CAMLR Convention'). Nevertheless, CCAMLR is not strictly an RFMO in the traditional sense, although it does perform fisheries functions within its geographical purview and 'qualifies as an RFMO in the sense of the 1995 Fish Stocks Agreement': EJ Molenaar, 'CCAMLR and Southern Ocean Fisheries' (2001) 16(3) International Journal of Marine and Coastal Law 465-499, at p. 496.

37 Article viI.

38 Article XIv.

39 Article II(1). Under Article II(2) this includes the 'rational use' of these resources, a concept that is left undefined in the Convention.
} 
of fin fish, molluscs, crustaceans and all other species of living organisms, including birds, found south of the Antarctic Convergence. ${ }^{40}$ Article II(3) prescribes a series of conservation principles for these resources, whereby parties undertake to ensure that the levels of harvested populations do not fall below that which would prevent stable recruitment, to maintain ecological relationships between harvested, dependent and related populations and to prevent or minimise the risk of changes in the marine ecosystem that may not be reversible over two to three decades. The approach of CCAMLR to new and exploratory fisheries is accordingly framed within the context of these overarching objectives.

Fishing activities in the CAMLR Convention Area are undertaken predominantly for Antarctic (Dissostichus mawsoni) and Patagonian toothfish (Dissostichus eleginoides) and krill (Euphausia superba), alongside smaller operations for other crustaceans and squid. As outlined below, new and exploratory fisheries have been established to at least some degree for all such species under the auspices of CCAMLR, particularly in respect of toothfish.

\section{'New' and 'Exploratory' Fishing under CCAMLR}

Concerns have long been expressed that fishing activities in the Southern Ocean 'often started without adequate information being available to evaluate the fishery potential or the possible adverse impacts on the target, dependent or related populations.'41 Accordingly, on 9 October 1989, in its capacity as Convenor of the Working Group for the Development of Approaches to Conservation of Antarctic Marine Living Resources (WG-DAC), Australia circulated a discussion paper addressing approaches to 'new and developing fisheries, other than krill', ${ }^{42}$ in which it was considered that CCAMLR should receive prior notification of any impending fishery so that it 'may conduct a

\footnotetext{
$40 \quad$ Article I(2).

41 Report of the Eleventh Meeting of the Commission (CCAMLR-XI), para. 4.27. On the extensive history of experimental and exploratory fishing in these waters - which pre-dates the advent of CCAMLR by some margin - see K-H Kock, K Reid, J Croxall and S Nicol, 'Fisheries in the Southern Ocean: An Ecosystem Approach' (2007) 362 Philosophical Transactions of the Royal Society B 2333-2349, at pp. 2334-2335.

42 Document WG-DAC 89/3. At the material time, krill fisheries were not subject to their own particular Conservation Measure under CCAMLR. A separate Working Group on Krill was inaugurated in 1989, shortly after the Australian proposal was tabled, through which krillspecific fishing measures were intended to be developed. Nevertheless, as noted below, the regulatory regime for krill fishing has had an interpretive influence on new and exploratory fishing for toothfish under CCAMLR.
} 
preliminary evaluation of the fishery, and formulate approaches to conservation before the fishery develops beyond the exploratory phase. ${ }^{43}$

Accompanying these suggestions, it was advocated that new or developing fisheries - as such endeavours were then termed in the CCAMLR vernacular should be subject to two key stages of evaluation. In the Notification phase, consideration should be given to the 'best scientific information available' as to how the proposed fishery might interact with the wider Antarctic ecosystem, alongside an appraisal of the difficulties in quantifying prospective impacts upon both the target stock and dependent species. Thereafter, in the Assessment stage, CCAMLR would apply this information to investigate an upper level, below which the commercial development of the fishery may commence. ${ }^{44}$ At its Eighth Meeting, the parties therefore considered that developing fisheries ought to be subject to 'some form of regulation' so that they did not proceed more rapidly than the development of the data thresholds required to assess the potential ramifications of the fishery. ${ }^{45}$ To this end, the Scientific Committee was tasked with advising on the type of information required to assess potential yields and the ecological implications of the fishery, potential regulatory measures to be implemented during this process and an indication of the incumbent time scales so as to facilitate the eventual transition to full management. ${ }^{46}$

A Conservation Measure (См) on new fisheries was duly adopted by CCAMLR at its Tenth Meeting in $1991 .{ }^{47}$ In the interim, a Swedish proposal that any such activities ought to be subject to advance notification was endorsed by the parties ${ }^{48}$ and remains a fundamental element of the CCAMLR position concerning such fisheries. CM 31/X, which has since been replaced by CM 21-01, established the long-standing CCAMLR definition of a new fishery as being:

a fishery on a species using a particular fishing method in a statistical subarea or division for which:

$43 \quad$ Ibid., para 8.

44 Document WG-DAC 89/4: Approaches to Conservation in New and Developing Fisheries.

$45 \quad C C A M L R-V I I I(\mathrm{n} 16)$, para. 123.

46 Ibid.

47 См 31/x: Notification that Members are Considering Initiating a New Fishery.

48 Report of the Ninth Meeting of the Commission (CCAMLR-IX), para 9.8. Broad support was expressed for the principle of advance notice, although a number of delegations raised concerns over 'the legal implications of this measure, and appropriate definitions of new and developing fisheries': ibid., para 9.7. 
(i) information on distribution, abundance, demography, potential yield and stock identity from comprehensive research/surveys or exploratory fishing have not been submitted to CCAMLR; or

(ii) catch and effort data have never been submitted to CCAMLR; or

(iii) catch and effort data from the two most recent seasons in which fishing occurred have not been submitted to CCAMLR. ${ }^{49}$

Under this construction, any notification of a fishery targeting a previously unfished species, new fishing ground or new fishing technique will in principle constitute a new fishery. Additionally, and in keeping with the entrenched regulatory position on VMEs outlined below, any proposed bottom-trawling in the high seas areas of the CAMLR Convention Area is deemed to be a new fishery and will require the prior approval of the Commission. ${ }^{50}$

Where a new fishery is proposed, the Member in question is required to provide notice of its intent to fish three months in advance of the next regular CCAMLR meeting. ${ }^{51}$ The applicant is also required to submit a Fishery Operation Plan (FOP), which will include a full outline of the nature of the new fishery, its location, target species, gear to be used and proposed minimum catch levels, alongside biological information on the target species, potential by-catches, comparable data from similar fisheries and possible impacts upon VMEs, especially benthic communities. ${ }^{52}$ Proposals are contingent upon a commitment to implement a Data Collection Plan (DCP) that may be established for that fishery by the Scientific Committee; such fishing opportunities may then only be undertaken by vessels that are suitably equipped and configured to comply with all relevant conservation measures.

Exploratory fishing, on the other hand, was first considered under the auspices of CCAMLR in 1992, where concerns were expressed over past practices and the need to ensure that such fisheries 'should not be allowed to expand faster than the acquisition of information necessary to ensure that the fishery can and will be conducted in accordance with the principles set forth in Article II of the Convention.'53 With the previous position on new fisheries considered a 'useful mechanism' for precautionary regulation, ${ }^{54}$ alongside the clear

49 CM 21-01: Notification that Members are Considering Initiating a New Fishery, Article 1.

50 Article 2 and Annex 21-01/A.

51 CM 21-01, Article 3(i).

52 Article 3 (ii).

$53 \quad C C A M L R-X I$ (n 41), para. 4.28 .

54 Ibid., para 4.30. 
advantages presented by a robust commitment towards prior notification, ${ }^{55} \mathrm{CM}$ 65/XII (since replaced by CM 21-02) was adopted at the subsequent CCAMLR Meeting. At this juncture, exploratory fishing was rather prosaically defined as 'a fishery that was previously classified as a "new fishery"'. An exploratory fishery retains this status unless and until sufficient information is forthcoming to evaluate the distribution, abundance and demography of the target species, so as to provide an estimate of the fishery's potential yield, to review the impacts of the fishery upon dependent and related species and to allow the Scientific Committee to formulate and provide advice to the Commission on appropriate harvest catch levels, as well as effort levels and fishing gear, where appropriate. ${ }^{56}$

Similar obligations concerning the application process and data collection protocols established for new fisheries are required of those intending to enter notifications for exploratory fishing; hence such activities are also subject to the completion of a DCP and the prior submission of a FOP. Neither CM currently applies in the waters adjacent to the Kerguelen, Crozet or Prince Edward Islands, although the pertinent coastal states - France and South Africa respectively - 'agree in principle' with these requirements and have undertaken to inform the Commission of research progress and results for any new or exploratory fisheries conducted in these waters. ${ }^{57}$

Although the definitional requirements of CM 21-01 and CM 21-02 appear relatively clear and unambiguous, the implementation of these provisions by CCAMLR has nonetheless provoked some intriguing and arguably inconsistent outcomes. Issues of construction of the concepts of new and exploratory fisheries have arisen infrequently, but have predominantly concerned new methods of fishing for species that have been previously fished. Some such notifications have involved the use of techniques that are familiar to many fishing grounds but are nonetheless new to the CAMLR Convention Area, and in one instance novel technology was deployed for the fishing of krill. The management responses are revealing as to how strictly the definitional requirements outlined in these measures have been applied by CCAMLR, especially in the context of notifications by purported new participants.

\section{$55 \quad$ Ibid., para 4.32.}

56 Para 1(ii) of CM 21-02.

57 Report of the Twelfth Meeting of the Commission (CCAMLR-XII), para 8.6. Indeed, one of the first new fisheries to be established was developed within these waters by South Africa, which pledged that the spirit of the relevant provisions 'will be followed closely in managing the fishery': Report of the Fourteenth Meeting of the Commission (CCAMLR$X I V)$, para 6.3. 
The first significant evaluation by CCAMLR of the definitional parameters of new and exploratory fisheries occurred in 2005,58 concerning proposals for a technique termed 'continuous krill fishing'. Unlike traditional pelagic trawls, continuous fishing involves a pumping mechanism whereby air is injected into the cod-end of the net (i.e., the segment in which the catch is retained), funnelling a constant stream of krill into the vessel. This method offers the advantages of enhanced selectivity and a greater proportion of live krill taken in the catch; unlike traditional trawling, there is less scope for individual krill to be crushed in the net prior to landing. Continuous fishing appears to have been first undertaken on a tentative basis in the 2004/05 fishing season by a Vanuatu-flagged vessel, subsequently re-registered to Norway, following which the Norwegian delegation notified the Commission of its intentions to develop this technique more extensively for the following year. ${ }^{59}$

The question as to how the apparent novelty of this technique might affect the classification of these fishing efforts caused a degree of consternation within the Commission. Despite some reservations, the Scientific Committee acknowledged that krill fishing is evolving with regard to the pattern of operation, harvesting technology and participants and, accordingly, continuous fishing would not in its view be considered a form of new or exploratory fishing 'if there is an adequate description of the selectivity of the method for krill, a characterisation of the haul (or catch rate) and information on the location of krill catches'.60 This interpretation was challenged by Russia, which

58 Elements of new fishing techniques had been sporadically raised prior to this. In 2002, Australia notified the Commission of its intention to introduce long-lining for Patagonian toothfish in an established fishery in Division 58.5.2. As the notification was 'not formally' one for new or exploratory fishing, it was considered sufficient that the proposing Member had given advance notice of these adjustments and of the management provisions planned for that fishery: Report of the Twenty-First Meeting of the Commission (CCAMLR-XXI), para 9.4. Meanwhile, in 2004, the Scientific Committee failed to reach consensus over the definitional status of the proposed introduction of a limited degree of bottom-trawling, interspersed with mid-water trawls, for icefish: Report of the Twenty-Third Meeting of the Scientific Committee (SC-CCAMLR-XXIII), paras 4.127-4.134. Unmodified bottom-trawling had been previously classed as a new fishery by both the notifying Member (Australia) and the Scientific Committee: Report of the Twenty-First Meeting of the Scientific Committee (SC-CCAMLR-XXI), para 5.6.

59 Report of the Twenty-Fourth Meeting of the Commission (CCAMLR-XXIV), paras 4.234.24. There is no official record of prior consideration by CCAMLR of the status of these activities until they were transferred to Norwegian supervision.

6o Report of the Twenty-Fourth Meeting of Scientific Committee (SC-CCAMLR-XXIV), para 4.8 . 
considered that continuous fishing should be classified as an exploratory fishery until comprehensive data on its selectivity, the characteristics of the haul and species composition, location of the catches and haul duration had been generated and considered fully by the Scientific Committee. ${ }^{61}$ The Russian approach failed to attract further support and a degree of continuous fishing has prevailed in the CCAMLR krill fishery, notwithstanding a clear subsequent acknowledgment that this method has 'presented some unique challenges to recording effective fishing effort, catch and collection of biological data and by-catch data'. ${ }^{62}$ Perhaps mindful of these challenges, the operators of this system have complied assiduously with data-collection requirements, even if these have been formulated in the context of commercial krill fishing, as opposed to the specific regime for exploratory fishing in the CAMLR Convention Area. Although commentators have previously expressed reservations that 'the use of this system to reduce the ecosystem effects of fishing is still largely unproven because of its novelty', ${ }^{\prime} 3$ continuous fishing and cod-end pumping have nonetheless been endorsed by CCAMLR as accepted krill fishing techniques in these waters. ${ }^{64}$

The consideration by CCAMLR of the Norwegian continuous fishing method stands in marked contrast to that of a subsequent proposal by the Cook Islands to access the krill fishery. The Cook Islands acceded to the CAMLR Convention in 2005 and, in 2007, notified the Commission of its intention to commence pair trawling for krill. This was met with concerted opposition from a number of Members, which considered that as pair trawling had not been previously deployed in the Convention Area, it constituted a new method of catching krill and should therefore be more appropriately treated as a 'new' fishery. ${ }^{65}$ The Cook Islands contended that the proposed activity was not a new fishery and instead involved a mid-water trawl pursuant to the standard FAO

\footnotetext{
$61 \quad C C A M L R-X I V(\mathrm{n} 59)$, para 4.26.

62 Report of the Twenty-Fifth Meeting of the Commission (CCAMLR-XXV), para 4.42. At this juncture Russia again sought unsuccessfully to reclassify these endeavours as an exploratory fishery, on the basis that this would not impede the development of the fishery, while the specific framework for exploratory fishing activities might actually overcome some of the methodological and organisational difficulties experienced in implementing this new system: ibid., para 13.6.

63 S Nicol, J Foster and S Kawaguchi, 'The Fishery for Antarctic Krill - Recent Developments' (2012) 13(1) Fish and Fisheries 30-40, at p. 32.

64 См 21-03: Notifications of Intent to Participate in a Fishery for Euphausia superba; Annex A.

65 See in particular the response of New Zealand: Report of the Twenty-Sixth Meeting of the Commission (CCAMLR-XXVI), para 4.40.
} 
definition of such operations and was in essence 'the same method as currently employed in the fishery, which has already been substantially modified without consequence'.6 ${ }^{66}$ Nevertheless, the Commission considered that the proposal should be resubmitted in the following year as a notification for a new fishery, on the basis that there was no prior information on the impact, selectivity or catch data for the use of this method in the Convention Area, as required under CM 21-01. ${ }^{67}$

Taken on these terms, however, the practical distinction between the notification by the Cook Islands for pair trawling and the preceding deployment by Norway of the continuous fishing system is not immediately apparent: arguably neither notification would have technically met the conditions of CM 21-01 on an equally strict construction. Although CCAMLR has not been subsequently called upon to interpret the qualifying threshold for a new or exploratory fishery, the divergence between these approaches is nonetheless suggestive of a degree of inconsistency in the application of these requirements which, whether by accident or design, has operated in practice to the benefit of an existing Member of the Commission, yet to the detriment of a purported new participant in the krill fishery. ${ }^{68}$

A final issue concerning the interpretation of new and exploratory fisheries under CCAMLR relates to the position of so-called 'lapsed' fisheries, which have been abandoned for primarily commercial reasons. A fishery is deemed to be lapsed 'when an assessment is no longer current', ${ }^{69}$ a position not dissimilar to the knowledge base concerning new and exploratory fisheries. If a degree of fishing does eventually resume in these areas - which has not occurred thus far - it appears that they will 'be reopened according to precautionary principles' which will involve prior notification and a commitment to further data

$66 \quad$ Ibid., para 13.20.

67 Ibid., para 13.21.

68 The Cook Islands has not yet submitted a revised application for new fishing for krill using pair trawls and the prospects for such a notification thereby remain a matter of conjecture. It may be speculated whether, in principle, another new entrant might have proved more successful, or whether a 'conventional trawl' as envisaged by см 21-03 might have received a warmer response, given that New Zealand had expressed particular - and highly influential - concerns over the Cook Islands' proposal: ibid., paras 13.10-13.13.

69 Report of the Seventeenth Meeting of the Scientific Committee (SC-CCAMLR-XVII), para 5.26. As a case in point, having received no notifications or reports of fishing for a number of years, in 2009 CCAMLR declared a previous exploratory fishery for squid to have lapsed and the provisions pertaining to it - См 61-01 - were duly excised from the Schedule of Conservation Measures in Force: Report of the Twenty-Eighth Meeting of the Commission (CCAMLR-XXVIII), para 4.41. 
collection. ${ }^{70}$ If data are insufficient to make a satisfactory assessment before resuming fishing activities, a lapsed fishery will instead revert to a new fishery and will be subject to the procedures of $\mathrm{CM} 21-01{ }^{71}$ In either case, both avenues towards an eventual resumption of fishing in lapsed areas will accordingly be subject to precautionary management practices. A parallel position applies to fisheries that have been formally 'closed' by CCAMLR for conservation reasons, although as noted below, fishing for research purposes is currently undertaken in these areas in a manner that generally differs little from exploratory fishing, aside from its formal classification and oversight.

\section{Access to New and Exploratory Fisheries}

Participation in new and exploratory fisheries under CCAMLR is restricted solely to current Members of that body. ${ }^{72}$ This initially raised concerns as to the position of individual Member States of the European Union (EU) and, more specifically, whether those EU Member States that had yet to accede to the CAMLR Convention could exploit the general access entitlements awarded collectively to the EU to participate in exploratory fisheries, while conveniently by-passing the need to become a concurrent Member of CCAMLR, as was purportedly the case for Portugal in $1999 .^{73}$

Aside from a clear position on funding, ${ }^{74}$ the EU has only recently adopted legislation to regulate specific aspects of exploratory fishing pursuant to its Common Fisheries Policy (CFP), ${ }^{75}$ although a significant volume of such

$70 \quad$ Report of the Sixteenth Meeting of the Commission (CCAMLR-XVI), para 10.3.

71 SC-CCAMLR-XVII (n 69), para 5.26.

72 Para 5 of СM 21-02. This position is rather more implicit in relation to new fisheries under current CCAMLR rules, as CM 21-01 is ultimately silent on this requirement. However, a presumption that Members will establish and access new fisheries only under their own flags has constituted a distinct element of CCAMLR practice towards new fisheries from a preliminary stage: Report of the Fifteenth Meeting of the Commission (CCAMLR-XV), para 8.27 .

73 Report of the Eighteenth Meeting of the Commission (CCAMLR-XVIII), paras 9.42-9.52.

74 Public funding is not available for exploratory funding under current EU rules: see Articles 15(1) and 19(1) of Commission Regulation (EC) No 498/2007 of 26 March 2007 laying down detailed rules for the implementation of Council Regulation (EC) No 1198/2006 on the European Fisheries Fund [2007] Official Journal L120/1; see further R Churchill and D Owen, The EC Common Fisheries Policy (Oxford University Press, Oxford, 2009) at pp. 524-527.

75 Regulation (EU) No. 2016/2336 of the European Parliament and of the Council of 14 December 2016 establishing specific conditions for fishing deep-sea stocks in the north-east Atlantic and provisions for fishing in international waters of the north-east Atlantic and repealing Council Regulation (EC) No. 2347/2002 [2016] Official Journal 
fishing is undertaken outside Community waters by vessels of EU Member States, both within and beyond areas of national jurisdiction. ${ }^{76}$ In the context of CCAMLR, following staunch opposition by a number of Members, which insisted that the Portuguese arrangement 'should not set a precedent', ${ }^{77}$ a clear position was subsequently enshrined in the core EU Regulation on access to fishing opportunities under the CFP, specifying that '[o]nly those Member States which are members of the CCAMLR Commission' may participate in certain named exploratory fisheries in these waters. ${ }^{78}$

Beyond the specific context of EU fishing entitlements, the general requirement for CCAMLR Membership does not seemingly prevent a vessel from being reflagged mid-season to another Member to avail itself of more than one set of exploratory fishing opportunities in any given year. Where this is contemplated, the vessel must have completed the relevant registration procedures required by the authorities of the notified Member before entering that specific fishery. ${ }^{79}$ Reflagging in this particular context offers some advantage to the operator, since numerical restrictions have been placed upon access to nationally registered vessels in certain exploratory fisheries under particular

L 354/1. Under Article 8 the European Commission may approve applications for exploratory fishing at depths up to 8oom in locations beyond those in which existing fishing activities had occurred. On the development of the new legislation see GA Oanta, 'The European Union's Reform of Deep-Sea Fisheries in the North-East Atlantic' (2017) 32(3) International Journal of Marine and Coastal Law 589-6oo, at pp. 593-596.

76 Although little regulated within EU waters, this issue has nonetheless constituted a significant component of the Eu's system of Fisheries Partnership Agreements, concluded with a series of developing states, for which the majority have considered exploratory fishing to at least some degree. Indeed, provisions on exploratory activities have been elaborated in the case of Gabon, Guinea, Kiribati, Mozambique, the Seychelles, the Solomon Islands and, especially, Mauritania, which provides for extensive regulation: see further $\mathrm{N}$ van der Burgt, The Contribution of International Fisheries Law to Human Development: An Analysis of Multilateral and ACP-EU Fisheries Instruments (Martinus Nijhoff, Boston/ Leiden, 2013) at p. 300. As noted above (n 75) exploratory fisheries have also been pursued by EU-flagged vessels in the international waters of the north-east Atlantic region. CCAMLR-XVIII (n 73), para 9.52.

78 Council Regulation (EU) 2016/72 fixing for 2016 the fishing opportunities for certain fish stocks and groups of fish stocks, applicable in Union waters and, for Union fishing vessels, in certain non-Union waters, and amending Regulation (EU) 2015/104 [2016] Official Journal L 22/1; Article 26(1).

79 This position was clarified in 2011 in relation to the Antarctic Chieftain, a longstanding participant in exploratory fisheries that has alternated between the registries of Australia and New Zealand for particular fishing activities: Report of the Thirtieth Meeting of the Commission (CCAMLR-XXX), para 11.7; see also CM 21-02, para 5 . 
CMs. ${ }^{80}$ This is not the generic position for all exploratory fisheries, however: at a preliminary stage in the development of rules on exploratory fishing, the Members expressly rejected the principle of 'one member, one vessel' as applied in the specific context of crab fishing as having set a wider precedent for such endeavours generally, ${ }^{81}$ hence there is little incentive towards the wholesale reflagging of exploratory fishing vessels.

Access to new and exploratory fishing opportunities in the CCAMLR Area is contingent upon a record of good conduct, with rights of participation denied to any vessel that has been listed as having participated in Illegal, Unreported or Unregulated (IUU) fishing pursuant to CMs 10-06 and 10-07. ${ }^{82}$ Various CCAMLR Members have trenchantly opposed any softening of this position, ${ }^{83}$ although, as Serdy observes, this stance does little to deter serial recidivism in a region that has long generated concerns over the prevalence of illicit fishing. ${ }^{84}$ Indeed, neither of the pertinent CMs proffer a mechanism for the eventual rehabilitation of offending vessels in the context of new and exploratory fisheries. Provisional listing would also appear to disqualify a vessel from future exploratory fishing, in the view of a majority of Members, ${ }^{85}$ as would a failure to demonstrate that a vessel reasonably suspected of being in breach of other fishing rules has been subsequently deprived of the benefits of its activities ${ }^{86}$ Likewise, there has been growing frustration towards the failure

8o See, for instance, CM 41-11.

$81 \quad C C A M L R-X I V\left(\mathrm{n}_{57}\right)$, para. 8.42.

82 See para 9 of CM 21-01 and para 13 of СM 21-02.

83 Indeed, as argued by New Zealand - and enthusiastically supported by numerous other delegations - accepting purported notifications from vessels with a poor record of compliance with the various CCAMLR restrictions 'would make the Commission the object of public derision': Report of the Twenty-First Meeting ( $\mathrm{n}_{58} 8$ ), para 8.23.

84 A Serdy, 'Antarctic Fisheries Management' in EJ Molenaar, AG Oude Elferink and D Rothwell (eds), The Law of the Sea and the Polar Regions: Interactions between Global and Regional Regimes (Martinus Nijhoff, Leiden/Boston, 2013) 217-242, at p. 234. Individual Members have argued that a denial of access on this basis merely serves to perpetuate a cycle of IUU fishing - which remains a significant problem in a number of exploratory fisheries - although no agreement has yet been achieved on this issue: CCAMLR-XXVI (n 65), paras 10.44-10.46.

85 This point was raised in 2007 in relation to the Volna, a Russian-flagged vessel that had seemingly fished in the CCAMLR Area without notification and shortly thereafter sought to undertake exploratory fishing. Russia considered this to have been a domestic oversight, but found little support from the other Members for the future participation of this vessel in any of the CCAMLR exploratory fisheries: CCAMLR-XXVI, ibid., para 10.64.

86 This position arose in 2016, in the absence of confirmation that a Korean-flagged vessel had dumped an allegedly illegal catch and had thus been fully deprived of any apparent 
to fulfil the data-collection requirements of CM 21-01 and, especially, CM 21-02, which may constitute sufficient grounds 'for denying specific vessels future access to new and exploratory fisheries. ${ }^{37}$ The precise degree of leeway accorded to non-compliant vessels to remedy their conduct remains somewhat uncertain, although the strong reservations expressed towards particular vessels have tended to inspire pre-emptive action by the flag states to remove these participants from the fishery, rather than further testing the collective patience of the other Members. ${ }^{88}$

Where a new or exploratory fishery is established within the CAMLR Convention Area, and the various intended participants have met the relevant criteria for a successful notification, access to those fisheries will proceed on an equal and open basis between the Members. In this respect, and perhaps to the chagrin of those who have facilitated the development of a viable fishery ab initio, such operators will seemingly not receive favourable treatment once an exploratory fishery has transitioned to full commercial management.

It has been suggested that, in the context of the high seas, Article 119(1)(a) of the LOSC could be interpreted to support a degree of preferential treatment for particular companies, in a manner broadly analogous to the 'pioneer' status granted to certain seabed mining operators that have played a significant role in pursuing the technological innovations necessary to allow for the exploitation of these resources. ${ }^{89}$ The LosC is ultimately silent on the position of pioneer fishers and it appears unlikely that the creation of 'favourable conditions' for research opportunities envisaged under Article 243 extends to commercial inducements for pilot activities, having been primarily considered in the context of removing geopolitical obstacles to scientific endeavour. ${ }^{90}$ There

benefits of this activity. The Members agreed that exploratory fishing could not be undertaken by this vessel until this issue had been fully resolved: Report of the Thirty-Fifth Meeting of the Commission (CCAMLR-XXXV), para 3.13.

87 See in particular the comments of the Us delegation, which attracted considerable support among the other Members: Report of the Twenty-Ninth Meeting of the Commission (CCAMLR-XXIX), para 12.37.

88 Korea, for instance, has been prompted to withdraw purported notifications for exploratory fishing due to clear opposition from other Members over records of compliance: see further below $\mathrm{n} 110$ et seq.

89 EJ Molenaar, 'The South Tasman Rise Arrangement of 2000 and Other Initiatives on Management and Conservation of Orange Roughy' (2001) 16(1) International Journal of Marine and Coastal Law 77-124, at pp. 114-115.

9o The requirement to remove obstacles to research, which was not ultimately incorporated into Article 243, was advocated as a means of ensuring that scientific cooperation would not be stymied by Cold War constraints: S Rosenne and A Yankov (eds), United Nations 
is nonetheless an attractive logic to this argument, not least from the perspective of entrepreneurial fishing interests that have borne the financial risks and development costs incumbent in the fishery and the effort of facilitating the acquisition of the requisite data, but must then relinquish exclusivity to the benefit of enterprises that may have invested little or nothing in the eventual creation of a new fishery.

Fisheries 'pioneers' with a strong record of compliance with catch restrictions and data management requirements may nevertheless receive favourable treatment by their respective domestic authorities. ${ }^{91}$ This is not without significance in the context of new and exploratory fisheries, where particular states have adopted increasingly stringent requirements for the national endorsement of purported notifications. ${ }^{92}$ Nevertheless, there appears to be limited support for this approach within wider multilateral practice. At a preliminary stage in the formation of its policies towards new and exploratory fisheries, CCAMLR specified that such areas could not be reserved for the personal use of those who had pioneered their development and 'reaffirmed its understanding that none of these measures should in any way imply the scope and limitation to future participatory rights of individual Members for those fisheries. Members not currently participating in the new or exploratory fisheries will be entitled to enter the fisheries in subsequent exploratory or other phases on an equal basis.' ${ }^{93}$

Convention on the Law of the Sea 1982: A Commentary, Volume IV (Martinus Nijhoff, Dordrecht, 1990) at pp. 474-478.

91 Molenaar (n 89) at p. 115. Such a trend is discernible in Australian practice, for instance, which has incentivized domestic benefits for pioneer fishers.

92 See for instance Australian Fisheries Management Authority, Guide to CCAMLR New and Exploratory Fisheries (AFMA, Canberra, 2015) at pp. 7-8 (stating that notifications from Australian-flagged vessels will only be supported where they advance the national interest).

$93 \quad C C A M L R-X V\left(\mathrm{n}_{72}\right)$, para 9.13. A degree of assistance did however appear to be forthcoming to the Us in its intended prosecution of the Area $48.3 \mathrm{crab}$ fishery, as new notifications to this fishery were contingent upon fulfilling the Phase I research requirements of prior experimental fishing, which the individual us operator was considered to have met: Report of the Nineteenth Meeting of the Scientific Committee (SC-CCAMLR-XIX), paras 2.26 and 5.114. In principle, this would have given fishers that had completed these requirements a temporary advantage over other operators, at least while the conservative management scheme envisaged under см 181/XVIII was considered necessary. However, the fishery proved not to be commercially viable, and whereas the requirements of this measure are still technically applicable even in the absence of fishing activity, this benefit remains rather illusory in this particular context. 
Some scope for preferential treatment is tentatively considered under the South Pacific Regional Fisheries Management Organisation (SPRFMO) and the South-East Atlantic Fisheries Organisation (SEAFO), which are the only other bodies thus far to have engaged - albeit peripherally - with this question. The SPRFMO Convention expressly states that the 'contribution to the responsible development of new or exploratory fisheries' will be taken into account as a criterion in future participation in commercial fisheries. ${ }^{94}$ In and of itself, however, it is unclear whether this provision actively promotes the interests of pioneers or is instead intended to apply more punitively to vessels that breach the conditions for the conduct of exploratory fishing or consistently and unreasonably fail to return adequate data. As noted below, the limited practice of SPRFMO in this regard is suggestive of a more circumspect approach: recent measures concerning new and exploratory fisheries have stated categorically that such activities 'will not be considered to be a precedent for future allocation decisions, ${ }^{95}$ notwithstanding the tenor of Article 21(1)(i). Likewise, although the SEAFO Convention contains a similar clause, ${ }^{96}$ practice has been insufficient to confirm any degree of divergent intent to the CCAMLR position on pioneer fisheries in alternative fora.

Most significant, perhaps, in this regard is the negotiating history of Article 6(6) of the UNFSA, which is ultimately silent on the matter of individual privileges and implies a more egalitarian position within any resultant commercial fishery. During the Third Session of the negotiations, the new and exploratory fisheries clause of the Revised Negotiating Text was amended to include an obligation that conservative measures 'should be established as soon as possible in cooperation with those initiating the fishery.' ${ }^{97}$ Tellingly,

94 Convention on the Conservation and Management of High Seas Fishery Resources in the South Pacific Ocean (Auckland, 14 November 2009, in force 24 August 2012) [2012] ATS 28; Article 22(1)(i).

95 СмM 4.13 (Exploratory Fisheries; 2016) para 20; see n 155 et seq.

96 Convention on the Conservation and Management of Fishery Resources in the SouthEast Atlantic Ocean (Windhoek, 20 April 2001, in force 30 April 2003) 2221 UNTS 189; Article 2o(1)(f) states that in determining the nature and extent of participatory rights in fishing opportunities, the Commission will consider, inter alia, 'contributions to new or exploratory fisheries, taking account of the principles set out in article 6.6 of the 1995 Agreement'.

97 Document A/CONF.164/13.Rev.1 of 30 March 1994; reproduced in Lévy and Schram (n 13) at p. 440 (emphasis added). Little indication is publicly available as to the intended degree of cooperation required and the implications of this privileged status in this relatively short-lived version of the draft provision. Given the strong assertions of equal rights of access within CCAMLR at the material time, this suggested obligation appears to 
however, this wording was swiftly expunged from the text at the Fourth Session and remained absent from the final version of the UNFSA, representing a clear rejection of additional consultative entitlements for pioneer fishers.

\section{The Management of New and Exploratory Fisheries under CCAMLR}

The management of new and exploratory fisheries within the Southern Ocean has involved a concerted degree of regulatory improvisation on the part of the CCAMLR institutions. These policies were initially developed for king and stone crabs, which represented a pro-regime for the regulation of new and exploratory fisheries under CCAMLR, and have subsequently become more streamlined and standardised through a variety of CMs applied to specific toothfish fisheries that emerged in the late 199os.

New fisheries were first deliberated within CCAMLR in 1990, when the Us approved a domestic application for small-scale crab fishing in Area 48.3, although this permit was not ultimately used due to the prevailing weather conditions. The following year, in the light of agreement over the need for advance notice, the us voluntarily submitted a new application by the same operator to the Scientific Committee for a review of its research and data collection plan and accompanying environmental impact assessment, a move that was considered a 'useful example' of the steps needed to fulfil the requirements of (then) См 31/X.98 Under (then) см 6o/XI, the fishery was closed until a workshop could be convened to formalise the requisite data collection regime, pending the application of a 'conservative management strategy' ${ }^{99}$ To this end, the fishery was subsequently reclassified as 'exploratory' - a designation that prompted some initial unease in the absence of a clear definition of the term at that stage $\mathrm{e}^{100}$ - and prospective fishers were required to first complete an Experimental Harvest Regime before the more specific requirements of the conservative management strategy as elaborated in (then) CM 181/XVIII would

have been derived instead from the earlier draft convention tabled by Argentina, Canada, Chile, Iceland and New Zealand, which envisaged a stronger degree of initial management authority by coastal states and obligations of consultation if the fishery was not subsequently subsumed under the control of an RFMO.

98 Report of the Tenth Meeting of the Commission (CCAMLR-X), para 6.11.

$99 \quad C C A M L R-X I(\mathrm{n} 41)$, para 9.49. This process clearly influenced the concurrent UNFSA negotiations, with the new and exploratory fishing clause of the draft text also (then) advocating 'conservative' limits to be imposed on such activities: Document A/CONF.164/13 of 23 November 1993; reproduced in Lévy and Schram (n 13) at p. 75 .

$100 \quad$ CCAMLR-XIV (n 57), para 8.37. 
be applied. ${ }^{101}$ The fishery nevertheless swiftly fell into abeyance for economic reasons and, notwithstanding a brief Russian programme of experimental fishing, only ever yielded meagre harvests of crabs. It thus appears unlikely to be resurrected as an active concern. Nevertheless, this fishery has not been reclassified as either lapsed or closed and the regulatory regime considered under CM 52-01 would still apply to these stocks in framing any eventual transition to full management.

Seven exploratory fisheries, each of which concern toothfish, ${ }^{102}$ are currently operational within the CCAMLR network, with varying degrees of participation. In addition to the general requirements prescribed under CMS 21-01 and 21-02 for the notification of new and exploratory fisheries, particular conditions - including tagging obligations, observer coverage and data collection protocols - are established under CM 41-01 for the conduct of these activities, and limits on each exploratory fishery are prescribed through further individual CMs. ${ }^{103}$ This regulatory framework - which imposes clear restrictions upon fishing effort and retains a strong focus on prior approval, continuous scientific review and universal observer coverage - represents in principle a significant illustration of the precautionary approach to the management of vulnerable fish stocks and ecosystems in the face of considerable uncertainty.

In this respect, a degree of cautious optimism is appropriate. Despite the steady expansion of exploratory fishing within the CAMLR Convention Area, compliance with individual catch limits and observer coverage has generally

101 See further M Belchier, T Peatman and J Brown, "The Biology Ecology and Development of Fishery Management Advice for the Anomuran Crabs at South Georgia (CCAMLR Subarea 48.3) ' (2012) 19 CCAMLR Science 1-15, at pp. 10-11 (raising concerns about the sustainability of the enterprise if the precautionary limits were to be consistently reached). CM 52-01 currently applies to this fishery, within which the experimental harvest regime is now reproduced in Annex 52-01/B.

102 There is also some scope for tuna fishing activities, a species with a chequered history of under-regulated catches within the CAMLR Convention Area: see further A Hemmings, 'Regime Overlap in the Southern Ocean: The Case of Southern Bluefin Tuna and CCSBT in the CCAMLR Area' (2006) 3 New Zealand Yearbook of International Law 207-217. In October 2015 an Arrangement was concluded between CCAMLR and the Commission for the Conservation of Southern Bluefin Tuna (ССsвT). Participants in both organizations have generally agreed to pursue tuna allocations through the CCSBT, and CCAMLR has urged any future tuna fishing occurring within the CAMLR Convention Area to be regulated under the regime of new and exploratory fisheries: CCAMLR-XXV (n 62), para 16.40. Additionally, in October 2017, a small number CCAMLR Members indicated their intention to pursue exploratory fisheries for finfish in future seasons.

103 The limits for each exploratory fishery are established, respectively, under CMs 41-04, 4105, 41-06, 41-07, 41-09, 41-10 and 41-11. 
remained high. Catches in accordance with exploratory fishing protocols have predominantly met the prescribed limits for these fisheries, notwithstanding a small number of non-egregious breaches in individual fishing seasons. However, the management of new and exploratory fisheries under CCAMLR has not been without complications, for which some reservations may be legitimately expressed concerning the implementation of data-collection requirements. These concerns are not without significance, since the acquisition of data remains a core obligation under CMS 21-01 and 21-02 and ultimately constitutes the primary justification for both the initiation and the continuation of new and exploratory fisheries sanctioned within these waters.

Challenges in securing appropriate and sufficient data have been apparent since the inception of the CCAMLR exploratory fishing regime where, despite strong interest in pursuing these burgeoning opportunities as reflected by the considerable number of notifications for new and exploratory fisheries, relatively few such allocations were initially used. Although the threshold requirements are moderately low - a new fishery is deemed to have been prosecuted 'if some fishing effort had been applied'104 - for a number of years CCAMLR's new and exploratory fisheries were generally characterised by inactivity. ${ }^{105}$ This presented significant practical and financial difficulties for the Scientific Committee which, while loathe to act punitively towards unprosecuted notifications, ${ }^{106}$ was nonetheless obliged to expend considerable time and resources in reviewing each application in good faith, while receiving

$104 C C A M L R-X V(\mathrm{n} 72)$, para. 9.10. Although prosaically expressed, this is a significant distinction, because a prosecuted new fishery will be accordingly reclassified as an exploratory fishery in subsequent seasons.

105 Only a fraction of the initial notifications received by CCAMLR for new and exploratory fisheries were ultimately prosecuted: see further DGM Miller, EN Sabourenkov and DC Ramm, 'Managing Antarctic Marine Living Resources: The CCAMLR Approach' (2004) 19(3) International Journal of Marine and Coastal Law 317-363, at p. 328.

106 Unprosecuted notifications (i.e., notifications that were never ultimately pursued in that particular season) were rarely vexatious, however, with fishers often postponing their exploratory operations due to unduly hazardous nautical conditions in an extreme environment, unanticipated financial issues or, indeed, to improve their capacity to return meaningful data. Accordingly, it was considered 'inappropriate for the Commission to use sanctions as a means of reducing the number of such notifications': Report of the Twentieth Meeting of the Commission (CCAMLR-XX), para 7.6. Nevertheless, the Scientific Committee - which is rather more directly affected by this problem than the Commissionhas suggested that future fishing opportunities ought to be withheld for contracting parties that routinely fail to implement their notifications: Report of the Twenty-Sixth Meeting of the Scientific Committee (SC-CCAMLR-XXVI), para 3.46. 
paltry data in return. This process has since been streamlined further, providing clearer scope for the Scientific Committee to reject poorly formulated or untimely notifications and placing the initial burden of costs more directly upon the applicant, ${ }^{107}$ thereby mitigating this problem to a significant degree.

Notwithstanding high levels of compliance with effort restrictions in exploratory fisheries, concerns have been raised that data monitoring requirements have been circumvented by particular vessels, as deficiencies in tagging programmes (or, perhaps more pertinently, the retention of larger fish and the tag-and-release of less commercially valuable individuals) have threatened to distort and undermine the knowledge base generated by exploratory activities. ${ }^{108}$ In this respect, CCAMLR has broadly favoured the use of the carrot over that of the stick, having endorsed a tagging lottery launched in 2013 by the Coalition of Legal Toothfish Operators (COLTO) to incentivise effective monitoring programmes. Stronger sanctions remain, however, and a persistent failure to comply with the requirements of CM 21-02 ought in principle to bar a vessel from future exploratory fishing. ${ }^{109}$ Indeed, a history of providing anomalous data has seen at least two vessels unilaterally withdrawn from the fishery by the flag state and subsequently precluded from further exploratory fishing opportunities. ${ }^{110}$

Some difficulties have also been posed by changes in personnel involved in exploratory fisheries, with experienced operators that had gained an affinity with the practical demands of research fishing having been steadily replaced by crews that are less accomplished at performing these requirements. ${ }^{111}$ Nevertheless as CCAMLR has observed, poor data management is rather more

107 Report of the Twenty-Second Meeting of the Commission (CCAMLR-XXII), para 3.19. Since 2003, an assessment fee has been levied for each individual notification, whereas in 2016 , CMS 21-01 and 21-02 were revised to stipulate that notifications for new and exploratory fishing will be subject to 'an administrative cost-recovery scheme and shall therefore be accompanied by a payment per vessel'.

108 Report of the Thirty-First Meeting of the Scientific Committee (SC-CCAMLR-XXXI), para 3.127.

109 See the discussion at $\mathrm{n} 87$ et seq.

110 Report of the Thirty-Second Meeting of the Commission (CCAMLR-XXXII), para 5.63. The Korean-flagged vessels in question were subsequently considered to have committed IUU fishing and would accordingly be disqualified from future exploratory fishing under the requirements of $\mathrm{CM}$ 21-02. It is illuminating to note that considerable pressure was applied by the other Members for the flag state to act decisively in this respect.

111 Report of the Working Group on Fish Stock Assessment 2012, para 5.21. This body has raised concerns as to the prospective implications of these less culpable errors on the evaluation and implementation of research plans. 
frequently attributable to the 'low commitment' of particular vessels towards implementing research plans ${ }^{112}$ and practical errors in setting research hauls, ${ }^{113}$ both of which are factors for which the threat of more permanent consequences could inspire rapid methodological improvements. Indeed, some delegations have argued that past tagging performance should also be reviewed when evaluating notifications, given the considerable variability experienced between particular operators in this respect, ${ }^{114}$ although it has not as yet been deemed necessary to impose this approach as an official management policy.

Where pertinent information has been forthcoming, concerns have also been raised by the Scientific Committee that a number of participants in exploratory fisheries have consistently failed to return meaningful data on marine ecosystems or dependent species, tending instead to focus primarily upon assessments of the target stock. ${ }^{115}$ Indeed, individual Members have observed that notifications for exploratory fishing have often neglected to include reference to dependent or related species or other ecosystem considerations, notwithstanding the clear requirements of CM 21-02. ${ }^{116}$ Although the commercial promise vested in exploratory fishing renders stock assessment a natural priority for fishers, the lack of attention to these factors has not been substantively addressed, which has clear implications for the ability of CCAMLR to advance the precautionary management of such fisheries. Managing the information that has been received nevertheless also raises practical difficulties, as valuable data on the wider environment generated by exploratory fishing has not always been effectively administered: for instance, studies on the role of fish within the Antarctic ecosystem 'has not typically found a home within working groups' growing commitments.'117

Data-collection challenges have been further compounded by the variable participation within exploratory fisheries pursued under CCAMLR, which renders the volume and quantity of information yielded from such fishing highly uneven. At one end of the scale, in certain exploratory fisheries - notably those of the Ross Sea in Divisions 88.1 and 88.2 - a comparatively high number of vessels have notified their intent to pursue an ultimately modest collective

\footnotetext{
112 CCAMLR-XXVIII (n 69), para 11.7.

113 Report of the Twenty-Eighth Meeting of the Scientific Committee (SC-CCAMLR-XXVIII), para 11.7 .

114 CCAMLR-XXIX (n 87), para 11.21.

115 Report of the Thirty-Fourth Meeting of the Commission (CCAMLR-XXXIV), para 9.19.

116 See especially the comments of the Swedish delegation, ibid., para 9.19.

117 Report of the Thirty-Fourth Meeting of the Scientific Committee (SC-CCAMLR-XXXIV), para 3.16o.
} 
allocation. This has raised the spectre of over-capacity in these waters, and the Scientific Committee has repeatedly warned that exploratory fisheries may become unsustainable if they are consistently fished to the full extent notified by the Members. This trend is nonetheless perpetuated by the current 'Olympic-style' fishing arrangements for these waters, since the unresolved question of sovereignty in Antarctica precludes the allocation of fishing opportunities via controlled national quotas, as may be imposed under more orthodox RFMOs.

In 2011, the Commission urged 'restraint' in the development of particular exploratory fisheries and called upon the Members to apply internal restrictions upon capacity and effort in such endeavours. ${ }^{118}$ This call has been heeded by the main participants: the Australian authorities, for instance, have significantly strengthened the approval process for exploratory fishing, specifying that notifications will only be supported if they are in the national interest and meet stringent domestic requirements, ${ }^{119}$ while New Zealand has on occasion voluntarily withdrawn notifications in response to CCAMLR's concerns over sustainability. ${ }^{120}$

Although the prospect of over-capacity within the Ross Sea remains a lingering concern, CCAMLR has been consistently confronted with the converse problem in other exploratory fisheries, which have remained generally undersubscribed and are unlikely to yield sufficient data to further assess the merits of their continued application. For instance, the multiple exploratory fisheries in Divisions 58.4 and 48.6 have produced limited information on the status of the stock, despite having operated for a number of years. This position begs a somewhat more existential question of the regime for new and exploratory fisheries: should such programmes remain open in virtual perpetuity, despite routinely generating modest results? Such an approach potentially undermines the precautionary nature of this framework, serving to facilitate continued fishing with little prospect of reliably confirming its environmental feasibility. Indeed, the Members have long recognised that where extended periods of exploratory fishing continue without the requisite assessments being possible, 'some of these fisheries are de facto commercial fisheries,',121

\footnotetext{
$118 C C A M L R-X X X$ (n 79), para 12.53.

119 AFMA (n 92) at pp. 7-8.

120 For instance, given an initially high level of participation in in Division 58.4.4, New Zealand withdrew its notification 'in the spirit of' the preamble of (then) CM 65/XII: CCAMLR-XX (n 106), para 7.9.

121 CCAMLR Symposium, 5-8 April 2005, Universidad Austral de Chile, Valdivia; Volume 1: Report of the Chairs, 6 (available online at http://www.antarctica.gov.au/law-and-treaty/
} 
an outcome that the system was expressly developed to avoid. Thus far CCAM LR has resisted imposing temporal limits on the operation of exploratory fisheries, an option that is available in principle to other regulators. ${ }^{22}$ As this shortfall is not attributable to obvious misconduct within the fishery, CCAMLR has taken a more pragmatic view of the situation, seemingly considering that the intrinsic value of generating some data currently outweighs the regulatory merits of closing particular areas and thereby receiving none. Moreover, it is recognised that intended fishing activities in a challenging environment are not always feasible in any given season and that valuable data may also be compromised by extrinsic factors beyond the control of the fishers. ${ }^{123}$

One approach towards addressing the significant variability experienced between such programmes has been to introduce separate nomenclature and, prospectively, distinct expectations - for particular exploratory fisheries. In 2010 an additional sub-category of 'Data-Poor Exploratory Fisheries' was identified by the Scientific Committee to denote 'all those fisheries that are closed or exploratory fisheries for which stock assessments are lacking,, ${ }^{124}$ with specific reference to Subarea 48.6 and Divisions 58.4.1 and 58.4.2, which have consistently yielded limited data despite having been operational for a considerable period of time. Problems in obtaining accurate data from these fisheries, especially those conducted in Divisions 58.4.1 and 58.4.2, have been compounded by the scale of IUU fishing in these waters, which is 'huge, often surpassing the legal take.125 This combination of challenges has led to Data-Poor Exploratory Fisheries being recently considered in a degree of isolation to other exploratory fisheries within CCAMLR, even if their qualifying feature - a lack of sufficient information to facilitate more orthodox regulation - is essentially

ccamlr/symposium-in-chile-2005), at which a mooted five-year limit for individual exploratory fisheries failed to find favour within CCAMLR.

122 For instance, SPRFMO contemplates a ten-year limit for exploratory fisheries - although, as noted below, practice is insufficient to determine whether this will be stringently applied and this body has to date largely elaborated its policies towards such activities based on the CCAMLR model.

123 Indeed, in one memorable instance extensive catch data from exploratory longlining were consumed by an opportunistic pod of orcas: Report of the Thirtieth Meeting of the Scientific Committee (SC-CCAMLR-XXX), para 3.123.

124 Report of the Twenty-Ninth Meeting of the Scientific Committee (SC-CCAMLR-XXIX), para 3.126. This appears to have been a term of art to distinguish the exploratory fisheries of the Ross Sea, which were considered by that point to have met the data-collection requirements of CM 21-02, from other exploratory fisheries in the CCAMLR Area: ibid., para 3.127.

125 DG Ainley and D Pauly, 'Fishing Down the Food Web of the Antarctic Continental Shelf and Slope' (2014) 50(1) Polar Record 92-107, at p. 96. 
indistinguishable from that of any other such fishery, which is inherently characterised by a paucity of data. Further discussions have duly occurred within CCAMLR as to whether alternative research programmes are appropriate for such fisheries, although particular delegations have opposed a softening of standards on the basis that the problem lies rather more in the implementation of these requirements than in their formulation..$^{126}$

Conceptual challenges to this approach aside, the sub-classification of exploratory fishing is indicative of a further-and essentially self-inflicted-malaise concerning the regulation of more specialised fishing regimes. In recent years, categories of non-commercial fishing have steadily proliferated, blurring the boundaries between forms of research-oriented activities. The additional complications raised by this approach are clearly reflected in recent developments in exploratory fishing under CCAMLR. ${ }^{127}$ In this regard, a significant volume of research fishing has been sanctioned in numerous closed areas, pursuant to CM 24-01, including extensive toothfish fisheries, which appear exploratory in all but name, yet are subject to more limited oversight within CCAMLR in comparison to the seven 'official' exploratory fisheries. ${ }^{128}$ Likewise, a distinct regime is envisaged for 'research fishing' that may be prospectively conducted in newly exposed marine areas, an activity that would also share the fundamental features of exploratory fishing, ${ }^{129}$ if not its nomenclature.

This broad trend further illustrates the increasing need to (re-)establish clearer definitional boundaries between research fishing regimes, for which

126 CCAMLR-XXX (n 79), para 11.11; this view has been expressed most forcefully by the Australian delegation, which has considered any distinction between individual exploratory fisheries to be fundamentally 'misleading', a view that it has strongly reiterated: CCAMLR-XXXIV (n 115), para 9.13.

127 Indeed, the Scientific Committee briefly mooted the amalgamation of the stages of 'new' and 'exploratory' fishing in 2008 , so that exploratory fishing would be simply extended to incorporate the first year of operation, as the rather more specific data-collection requirements of CM 21-02 could potentially provide a greater volume of information more swiftly: Report of the Twenty-Seventh Meeting of the Scientific Committee (SC-CCAMLR$X X V I I)$, para 4.186. This did not come to fruition and the distinction between the two categories of fishing remains intact.

128 Review of the CCAMLR Regulatory Framework and Recommendations for Streamlining Fishery Status; Document CCAMLR-XXXIV/17 Rev.1, 6-7.

129 See CM 24-04, paras 7, 8, 12 and 14, adopted at the Thirty-Fifth Meeting of the CCAMLR Commission in October 2016. Future research fishing in these areas under CM 24-04 will be seemingly conducted on a similar basis to new and exploratory fishing under CCAMLR, including requirements for full observer coverage, prior approval and the development of a research plan. 
the likely remedy will be a complex exercise in mapping the methodological distinctions between the various forms of non-commercial operations, or re-casting current research fishing more formally within the regime of exploratory fishing. Such a move is not without complications or conflict, however, with some CCAMLR Members reluctant to re-categorise closed fisheries as exploratory unless the stock status has changed in a manner that would render exploratory fishing sustainable, or unless this re-classification would provide a clearer basis to assess the stock in question. ${ }^{130}$ Nor indeed is the potential coagulation of sundry categories of non-commercial fishing unique to CCAMLR: the SPRFMO Convention, for instance, contemplates the conduct of 'research or exploratory fishing.'131 Likewise, as observed below, the notion of 'non-commercial fishing' has introduced further complexity to the ongoing 'Broader Process' on the international regulation of high seas fishing in the central Arctic Ocean.

\section{Towards a Transition to Managed Stocks? The Ross Sea Exploratory Fishery}

A question of key importance to the regulation of new and exploratory fisheries remains the conditions under which such activities may be eventually reformulated as commercial fisheries. Thus far, this process has yet to be formally concluded in relation to the various exploratory fisheries established under the auspices of CCAMLR. However, the toothfish fishery in Divisions 88.1 and 88.2 (the 'Ross Sea Exploratory Fishery'132) has approached this transition point, with the Working Group on Fish Stock Assessment (WG-FSA) having recommended that its present classification as an exploratory fishery be substituted for that of an established fishery. The process by which this stage has been reached under CCAMLR therefore represents the clearest current insight into how a transition might be managed, both within and beyond the Southern Ocean.

New fisheries within the Ross Sea area in Divisions 88.1 and 88.2 were first notified in 1997, primarily for Antarctic toothfish. In contrast to other exploratory fisheries outlined above, by 2001 it was observed that catches and

\footnotetext{
130 As was, for instance, the clear viewpoint of the USA: ibid., para 9.15.

131 Article 22(2); emphasis added.

132 Specific management measures for exploratory fisheries in the Ross Sea are addressed through CMs 41-09 and 41-10. These fisheries have tended to be treated holistically by CCAMLR as the 'Ross Sea exploratory toothfish fishery', although consensus has not been reached on amalgamating the governance of all such initiatives within Divisions 88.1 and 88.2 into a single См: CCAMLR-XXXII (n 110), para 5.34.
} 
participation in this region were significantly more buoyant, albeit at levels some considerable margin below the set limits. ${ }^{133}$ This attracted a steady influx of additional notifications and, by 2004, the Commission observed with concern that the Division 88.1 exploratory fishery 'now had the largest number of vessels fishing in any of the CCAMLR statistical areas.'134 Nevertheless, this increase in participation also meant that by 2005 the necessary geographical spread of fishing had been achieved and the requirement to conduct specific research sets under CM 41-01 could be lifted for these Divisions. ${ }^{135}$

By 2010, the WG-FSA considered that these exploratory fisheries had formally met the data-collection requirements of CM 21-02 and the research and assessment work undertaken in these areas had enabled it to effectively evaluate the distribution, abundance and demography of the target species, allowing for reliable projections of the potential impact of regular fishing at clearly defined levels upon dependant and related species. ${ }^{136}$ Accordingly, the following year, the WG-FSA tabled a formal document advocating the Ross Sea fishery be re-categorised as an established fishery. ${ }^{137}$ However, the Scientific Committee stopped short of recommending this outcome to the Commission, considering that the various CMs applicable to these exploratory fisheries had engendered a framework for research, assessment and data collection 'which had been essential for reaching this status and whose retention would be essential in the future.'138 Formal endorsement of a transition to commercial management has thus been postponed, pending further advice from the WG-FSA concerning the methodologies for ensuring that such data continue to be collated and assessed under more commercialised fishing conditions. Nevertheless, the status of this fishery has been further complicated by the designation of an extensive marine protected area for the Ross Sea region, effective from December 2017.

133 CCAMLR-XX (n 106), para 7.2. As Ainley and Pauly observe, fishers within this particular area swiftly perfected the techniques for catching toothfish in these waters, which may further explain the discrepancy in yields between CCAMLR's exploratory fisheries: (n 125) 95 .

134 Report of the Twenty-Third Meeting of the Commission (CCAMLR-XXIII), para 9.12.

135 SC-CCAMLR-XXIV (n 6o), paras 4.135-4.136.

$136 S C-C C A M L R-X X I X(\mathrm{n} 124)$, para 3.129. On the role of exploratory fishing in mapping the ecological characteristics of Antarctic toothfish in this region see S Hanchet, A Dunn, S Parker, P Horn, D Stevens and S Mormede,'The Antarctic Toothfish (Dissostichus mawsoni): Biology, Ecology, and Life History in the Ross Sea Region' (2015) 761(1) Hydrobiologia 397-414, at pp. 398-412.

137 The Ross Sea Toothfish Fishery: Proposal of Conditional Transition of Classification from Exploratory to Established; Document WG-FSA-11/32.

138 SC-CCAMLR-XXX (n 123), para 3.179. 
Under these arrangements, current fishing activities are scheduled to continue in these waters pursuant to CMs 41-09 and 41-10, alongside the emerging bespoke management regime for this area, ${ }^{139}$ which may ultimately inhibit the envisaged future transition to commercial management of these exploratory fisheries.

Notwithstanding the evolving arrangements for the Ross Sea fishery in general, concerns have been raised that a proposed transition process may be somewhat premature. Although the data-collection requirements stipulated by CM 21-02 are deemed to have been met, substantial gaps nevertheless remain in the knowledge base concerning toothfish in this region. For instance, information as to the full-year life-cycle of toothfish is incomplete, given that exploratory fishing activities occur within a seasonally limited window of time each year and there is little scope to obtain fisheries-independent data for this species. ${ }^{140}$

Critics of the current regime have argued that these arrangements are insufficiently nuanced to facilitate the effective implementation of the precautionary approach, citing an inadequate ecosystem monitoring programme within these fisheries and questioning whether the framework has been applied in a genuinely adaptive manner, given that the data generated thus far have resulted in little alteration to the annual quota. ${ }^{141}$ This has led to calls to curtail fishing effort within the Ross Sea exploratory fishery ${ }^{142}$ and even for a moratorium on further activities. ${ }^{143}$ These misgivings have been trenchantly rejected

139 CM 91-05 (2016): Ross Sea Region Marine Protected Area, para 28. Further requirements for fishing within the Special Research Zone of the Area, which includes exploratory fishing covered under CM 41-09, will enter into effect in 2020.

140 Hanchet et al. (n 136) at p. 411. There are also limited data on the importance of toothfish as a prey species to top predators within the Antarctic ecosystem: MH Pinkerton and JM Bradford-Grieve, 'Characterizing Foodweb Structure to Identify Potential Ecosystem Effects of Fishing in the Ross Sea, Antarctica' (2014) 71(7) ICES Journal of Marine Science $1542-1553$, at p. 1550 .

141 PA Abrams, DG Ainley, LK Blight, PK Dayton, JT Eastman and JL Jacquet, 'Necessary Elements of Precautionary Management: Implications for the Antarctic Toothfish' (2016) 17(4) Fish and Fisheries 1152-1174, at pp. 1156-1159; see also PA Abrams, 'How Precautionary is the Policy Governing the Ross Sea Antarctic Toothfish (Dissostichus mawsoni) Fishery?' (2014) 26(1) Antarctic Science 3-14.

142 Abrams et al. (n 141) at p. 1170.

143 LK Blight, DG Ainley, SF Ackley, G Ballard, T Ballerini, RL Brownell Jr., C-HC Cheng, M Chiantore, D Costa, MC Coulter, P Dayton, AL Devries, R Dunbar, S Earle, JT Eastman, SD Emslie, CW Evans, RA Garrott, S Kim, G Kooyman, A Lescroël, M Lizotte, M Massaro, S Olmastroni, PJ Ponganis, J Russell, DB Siniff, WO Smith Jr., BS Stewart, I Stirling, 
by members of the CCAMLR Scientific Committee, who have asserted that the Ross Sea arrangements represent 'best practice for precautionary management of developing fisheries in an ecosystem context' and have justified the methodologies employed as having allowed the fishery to develop 'in a steady and orderly fashion... whilst maintaining the catch levels commensurate with the data and knowledge available at the time.'144

Viewed as a unique test case of the implementation of regulatory requirements for exploratory fishing, it appears from the Ross Sea context that, if such activities were re-classified as commercial enterprises, a degree of transitional management is likely to occur and further research and data collection obligations would still be incumbent upon participants, at least in the short-term. In this manner, CCAMLR recognises that newly managed fisheries ought to be regulated more strictly in comparison to pre-existing fisheries as a core component of its application of the precautionary approach. It may be speculated that the imposition of ongoing research requirements embodies a regulatory compromise inherent in balancing the lack of scientific certainty derived from exploratory fisheries against the fulfilment of the specified terms of CM 21-02. Nevertheless, the practical mechanics of any post-exploratory management system have yet to be finalised by the WG-FSA and endorsed by the Scientific Committee. Accordingly, for the foreseeable future the management of the Ross Sea exploratory toothfish fishery will continue under the direction of CMS 41-09 and 41-10. In the meantime, however, it may be observed that this particular exploratory fishery has in recent seasons operated as a de facto commercial enterprise, exhibiting problems familiar to many other global fisheries: notably increasing capacity, combined with the steady migration of vessels between fishing opportunities as exploratory management areas have been successively closed due to the available catch limits being rapidly met or exceeded. ${ }^{145}$

JWillis, PWilson and EJ Woehler,'Fishing for Data in the Ross Sea' (2010) 330 Science 1316, at p. 1316.

144 S Hanchet, K Sainsbury, D Butterworth and C Darby, 'CCAMLR's Precautionary Approach to Management Focusing on Ross Sea Toothfish Fishery' (2015) 27(4) Antarctic Science 333-340, at p. 340.

145 On overcapacity see Report of the Thirty-First Meeting of the Commission (CCAMLR$X X X I)$, para 5.25; on current fishing and vessel practices see Report of the Thirty-Third Meeting of the Commission (CCAMLR-XXXIII), paras 5.33-5.36. 


\section{Emerging Regimes for New and Exploratory Fishing}

Beyond the auspices of CCAMLR, specific regulatory powers over new and exploratory fishing have been conferred upon a growing number of RFMOs, notably those instituted following the adoption of the UNFSA. Thus far, however, these mandates have been generally exercised in a limited manner. As a notable exception, SPRFMO has established a comprehensive framework for new and exploratory fisheries based largely upon the model pioneered by CCAMLR, with which it shares a regulatory boundary, a number of mutual parties and, prospectively, a series of overlapping fish stocks. Originating from trilateral negotiations in 2006 between Australia, Chile and New Zealand to address fisheries resources in the South Pacific region, the SPRFMo Convention was concluded in 2009 and entered into force in August 2012. Despite having only been in effect for a relatively brief period of time, SPRFMO has swiftly emerged as one of the more far-sighted fisheries bodies presently in operation. Indeed, at a preliminary stage in the negotiations it was determined that SPRFMO would transcend the basic principles of the UNFSA, which was seen as a useful regulatory template but representative only of minimum requirements for fisheries management. ${ }^{146}$ The resulting formulation of the SPRFMO Convention has been duly lauded as having 'raised the legal standard for international fisheries management' for, inter alia, new and exploratory fisheries. ${ }^{147}$

Reflecting this proactive regulatory philosophy, the SPRFMO Convention has advanced the most extensive framework for new and exploratory fisheries of the current post-UNFSA RFMOS. To this end, Article 22(1) provides that:

[a] fishery that has not been subject to fishing or has not been subject to fishing with a particular gear type or technique for ten years or more shall be opened as a fishery or opened to fishing with such gear type or technique only when the Commission has adopted cautious preliminary conservation and management measures in respect of that fishery, and, as appropriate, non-target and associated or dependent species, and appropriate measures to protect the marine ecosystem in which that fishery occurs from adverse impacts of fishing activities.

146 Y Takei, Filling Regulatory Gaps in High Seas Fishing: Discrete Stocks, Deep-Sea Fisheries and Vulnerable Marine Ecosystems (Martinus Nijhoff, Leiden/Boston, 2013) at pp. 210-211.

147 Report of the resumed Review Conference on the Agreement for the Implementation of the Provisions of the United Nations Convention on the Law of the Sea of 10 December 1982 relating to the Conservation and Management of Straddling Fish Stocks and Highly Migratory Fish Stocks; Document A/CONF/210/2010/7, para 37. 
Echoing key components of the CCAMLR approach, the SPRFMO Convention further considers that appropriate conservation and management measures (CMMs) will include prior notification, observer coverage, the submission of a development plan, data-collection requirements and mitigation measures to prevent adverse impacts upon marine ecosystems, ${ }^{148}$ and also facilitating the adoption of specific CMMs to advance the precautionary regulation of new and exploratory fisheries. In keeping with the broad conditions of Article 6(6) of the UNFSA, such measures

shall ensure that the new fishing resource is developed on a precautionary and gradual basis until sufficient information is acquired to enable the Commission to adopt appropriately detailed conservation and management measures. ${ }^{149}$

Despite the comprehensive formulation of Article 22, the SPRFMO Convention nonetheless retains some scope for future interpretive difficulties, not least concerning the notion of a 'fishery'. Although the SPRFMo Convention advances extensive definitions of 'fisheries resources', 'fishing' and 'fishing vessels,', 150 the preceding negotiations revealed conflicting perspectives on the legal status of previously unfished stocks. Indeed, whereas some delegations sought to expressly integrate such resources within the regime of Article 22, others considered that a 'target fishery' would be established where some effort had been applied to a particular species anywhere within the SPRFMO Area, irrespective of the absence of prior fishing activities within a specific location. This latter interpretation would appear to be out of kilter with the broad spirit of Article 6(6) of the UNFSA - and prevailing CCAMLR practiceyet in principle remains an open question, as the concept of a target fishery failed to graduate into the final wording of the Convention and the term 'fishery' accordingly remains undefined. ${ }^{151}$

These divergent negotiating positions notwithstanding, few interpretive complications have ultimately afflicted the limited SPRFMO practice to date. Nevertheless, in 2015 the SPRFmo Scientific Committee observed that, despite the general terms of Article 22, the 'Convention and existing смMs and standards provided little guidance for the development and approval of

\footnotetext{
148 Article 22(2).

149 Ibid. Similarly, under Article 3(2)(a), the precautionary approach 'as described in' the UNFSA and Code of Conduct is to be applied in the SPRFmo Convention Area.

$150 \quad$ Article $1(1)(\mathrm{f})$, (g) and (h).

$15^{1}$ See further Takei (n 146) at p. 219.
} 
exploratory fishing proposals.' ${ }^{152}$ These concerns, coupled with the first formal application to undertake exploratory fishing in the SPRFMO Area, resulted in the adoption in 2016 of two distinct CMMs to further advance the practical requirements for such activities.

To this end, CMM 4.13 (Exploratory Fisheries; 2016) expands and modifies the scope and application of Article 22, with such activities collectively considered 'exploratory fisheries.' ${ }^{153}$ As with the CCAM LR regime, CMM 4.13 mandates the prior submission and approval of a Fisheries Operation Plan, from which the Scientific Committee will establish a Data Collection Plan outlining the research requirements incumbent on fishers. Unlike the CCAMLR approach, however, SPRFMO prospectively adopts a stronger stance against a failure to submit the requisite data, with Members and Cooperating Non-Contracting Parties to be prohibited from participating in future exploratory fishing until fullinformationfrom previousactivitieshasbeen provided to theCommission. ${ }^{154}$ This reinforces the ethos that participation in exploratory fisheries remains a privilege rather than an entitlement in these waters: as noted above, СмM 4.13 adopts a similarly restrictive position to CCAMLR in managing the expectations of 'pioneer' fishers, for which Article 21(1)(i) of the SPRFMO Convention will be seemingly interpreted in a negative fashion to punish infractions by curtailing future fishing opportunities, rather than actively promoting the pursuit of additional fisheries. ${ }^{155}$

Significantly, CMM 4.13 also elaborates conditions for the future transition of exploratory activities to established fisheries. In this regard, the Commission may approve an application to manage an exploratory fishery as an established fishery where it is satisfied that sufficient information is available to: evaluate the distribution, abundance and demography of the target species to inform an estimate of the fishery's potential yield; review the impact of the exploratory fishery upon non-target, associated or dependant species and the accompanying ecosystem; and allow the Scientific Committee to formulate appropriate management arrangements. ${ }^{156}$ In contrast to CCAMLR's enduring collection of

\footnotetext{
$15^{2}$ Report of the Third Scientific Committee Meeting at p. 10.

153 Para 2.

154 Para 17.

155 See n 95 et seq. The Scientific Committee has also emphasized that, irrespective of exemplary conduct, exploratory fishing offers no guarantee that such activities will be approved in the future, or that the fleet in question will attain any operative advantage should the fishery ultimately transition to commercial management: Report of the Third Scientific Committee Meeting (n 152) at p. 10.

156 Para 24.
} 
'Data-Poor Exploratory Fisheries', см 4.13 seemingly contemplates a ten-year limit on the operation of any SPRFMO exploratory fishery, at which point the fishery will be either closed or reconstituted as an established fishery. ${ }^{157}$ The controversy surrounding the intended commercialisation of CCAMLR's Ross Sea Exploratory Fishery nevertheless suggests that some additional flexibility may be required in interpreting these deadlines, unless sufficient quantities of pertinent data can be yielded in a relatively truncated timeframe. With CMM 4.13 due to be reviewed in 2019, it is unclear whether SPRFMO will ultimately adopt the more permissive approach of CCAMLR towards the lifespan of exploratory fisheries - an outcome that could in principle be facilitated under this provision ${ }^{158}$ - or, indeed, whether a further ten-year period must elapse following closure in order for a fishery to be re-categorised as exploratory under Article 22(1) and for this regulatory cycle to commence anew.

Thus far, exploratory fishing within the SPRFMO Area remains in its comparative infancy, and applicable policies have generally mirrored those of CCAMLR in substance and scope. In 2015 New Zealand applied for a modest exploratory catch of toothfish, a species that had not been fished for over ten years in these waters, thus triggering the application of Article 22 for the first time. Given that no specific procedure had been elaborated for proposed exploratory fishing at the material time - and with longstanding experience of pursuing such activities in the Southern Ocean - the documentation submitted by New Zealand largely followed the CCAMLR template, which was applauded by the Sprfmo Scientific Committee as 'a systematic and controlled approach to exploratory fishing. ${ }^{159}$ This de facto alignment with the documentary requirements of CCAMLR offers significant practical benefits, given that the SPRFMO exploratory fishery essentially represents an extension of current activities conducted by New Zealand in an adjacent sector of the CAMLR Convention Area. Moreover, an additional смм governing these specific activities observed that, due to the likelihood of shared stocks between the two bodies, the conduct of exploratory toothfish fishing should follow pertinent CCAMLR rules. ${ }^{160}$

\footnotetext{
157 Para 23.

158 Para 4(c) considers a fishery to be 'exploratory' if it has been undertaken within the previous ten years pursuant to СMM 4.13 and a decision has yet to be taken by SPRFMO as to its status.

159 Report of the Third Scientific Committee Meeting (n 152$)$ at p. 9. The CCAM LR model proved a useful template, alongside the specific SPRFMo documentation concerning bottom fishing discussed below.

16o CMM 4.14 (Exploratory Toothfish Fishing; 2016), para 16.
} 
The first SPRFMO exploratory fishery, opened in 2016, has therefore utilised standard CCAMLR mitigation measures, observation policies and administrative processes, with this regulatory cross-pollination 'meeting or exceeding SPRFMO requirements.'161 Although a full evaluation of SPRFMO practice remains somewhat premature - restricted thus far to one limited expedition, conducted by personnel well versed in the CCAMLR requirements and yielding as yet unquantified but '[s]ignificant information'162 - there are at least promising indicators of future regulatory success, drawing upon the hard-learned best practices of CCAMLR and advancing strong commitments to sharing data to ensure a clearer understanding of the cumulative impacts of exploratory fishing across neighbouring RFMOs. ${ }^{163}$

A limited degree of exploratory fishing for toothfish has also commenced under the auspices of SEAFO. Unlike SPRFMO, the SEAFO Convention does not advance a specific provision on such activities, notwithstanding overarching commitments to apply the precautionary approach 'widely' 164 and to take account of the principles of Article 6(6) of the UNFSA in determining future participatory rights. ${ }^{165}$ Exploratory fisheries were subsequently defined by the SEAFo Scientific Committee in 2014 as 'fishing experiments solely or primarily aimed to discover new resources or new fishing grounds and are as such from the outset motivated by commercial interest', 166 a comparatively idiosyncratic formulation motivated primarily by a desire to clarify the concept of 'fisheries research'. This definition nonetheless presents scope for conflict with other more established constructions, especially as exploratory fishing under SEAFO is expressly distinguished from research fishing - whose main objective is to 'create a firm basis for fisheries management advice' - and is instead deemed 'less rigorous... which may typically not have to fully satisfy scientific best practice standards', with accompanying data-collection requirements 'rather a required by-product than a primary objective of the exploratory fishing effort'.167

\footnotetext{
161 Report of the Fourth Scientific Committee Meeting at p. 11.

162 Ibid.

163 СмM 4.14 mandates sharing this information with CCAMLR, a requirement first advocated by New Zealand in its initial application to conduct these activities. In 2015 an Agreement was adopted between SPRFMO and CCAMLR on future cooperation, including data exchange, which is clearly exemplified by current arrangements for exploratory fishing.

164 Article 7(1).

165 Article 20(1)(f).

166 Report of the Tenth Meeting of the Scientific Committee to SEAFO, para 23.1.

167 Ibid.
} 
This divergent approach sits uneasily alongside the neighbouring CCAMLR and SPRFMO regimes, which maintain a strong commitment towards targeted research objectives for exploratory fishing, as well as Article 6(6) of the UNFSA, which clearly mandates the assiduous collection of sufficient ecosystemdriven data before the commercialisation of a fishery may be contemplated. Likewise, there is little indication as to when a fishery or resource may be considered to be 'new', or whether the use of alternative gear in established fisheries might also trigger these requirements. The current concept of exploratory fishing under SEAFO is accordingly likely to require future modification to more centrally recognise the primary purpose of such activities - i.e., to cautiously ascertain the environmental, rather than the economic, feasibility of prospective fishing - as reflected under the UNFSA and current regional models of best practice.

Elsewhere, the regulation of new and exploratory fishing remains essentially prospective in nature. Among the other post-UNFSA RFMOs, regulatory powers over such activities have been conferred upon the Western and Central Pacific Fisheries Committee (WCPFC) - the constituent treaty of which reproduces Article 6(6) practically verbatim ${ }^{168}$ but has not yet exercised this mandate the North Pacific Fisheries Commission (NPFC), ${ }^{169}$ which entered into effect in mid-2015, and the Southern Indian Ocean Fisheries Agreement (SIOFA), ${ }^{170}$ which became operational in 2012, with exploratory activities limited thus

168 Convention on the Conservation and Management of Highly Migratory Fish Stocks in the Western and Central Pacific Ocean (Honolulu, 5 September 2000, in force 19 June 2004) 2275 UNTS 43; Article 6(5).

169 Convention on the Conservation and Management of High Seas Fisheries Resources in the North Pacific Ocean (Seoul, 1 April 2012, in force 19 July 2015; available online at http://npfc.r-cms.jp/About_Convention/). Under Article 7(3)(d) the Commission may 'establish the terms and conditions for any experimental, scientific, and exploratory fishing activities in the Convention Area', while Article $3(\mathrm{~h})$ obliges participants to ensure 'that any expansion of fishing effort, development of new or exploratory fisheries, or change in the gear used for existing fisheries, does not proceed without prior assessment of the impacts of those fishing activities on the long-term sustainability of fisheries resources and a determination that those activities would not have significant adverse impacts on vulnerable marine ecosystems, or ensuring that those activities are managed to prevent those impacts or are not authorized to proceed'.

170 Southern Indian Ocean Fisheries Agreement (Rome, 7 July 2006, in force 21 June 2012) 2835 UNTS 1. Article 6(3)(b) empowers the parties to 'allocate catch quantities for exploration and scientific research', while under Article 6(2) participation in fisheries should be determined in line with 'inter alia, international principles such as those contained in the 1995 [un Fish Stocks] Agreement'. 
far to domestic permits granted to three Korean vessels for the 2012/13 fishing season. ${ }^{171}$

Meanwhile, an express mandate for the supervision of 'experimental or exploratory fishing activities' has been 'retro-fitted' into the NAFo Convention, through a series of extensive textual revisions adopted in 2007 in order to promote an ecosystem approach to fisheries management, which eventually entered into effect on 18 May 2017. ${ }^{172}$ Notwithstanding the recent formalisation of these arrangements, NAFO has exhibited a clear regulatory intent towards emerging fisheries for a considerable period of time, first recognising the need to 'define and adopt precautionary strategies for the reopening of fisheries and for new and developing fisheries' ${ }^{\prime 173}$ in 1999. Moreover, throughout this interim period, many of these obligations had been applied provisionally, ${ }^{174}$ which has enabled NAFO to adopt a series of measures to regulate exploratory fisheries in the specific context of the protection of VMEs, as discussed further below.

Most recently, the multilateral regulation of new and exploratory fishing has been contemplated within the high seas portion of the central Arctic Ocean, an area currently devoid of commercial fishing but for which a substantial influx of valuable stocks has been projected in future decades. ${ }^{175}$ Although considerable scepticism remains as to whether the Arctic region will ultimately be transformed into an area of significant fisheries activity even within the long-term future, there has been considerable political interest in pre-emptive regulation to ensure that any prospective fishing is undertaken in a precautionary and environmentally sensitive manner. In July 2015, the five central Arctic Ocean coastal states adopted a Declaration Concerning the Prevention of Unregulated High Seas Fishing in the Central Arctic Ocean, ${ }^{176}$ recognising that

171 Report of the Second Meeting of the Parties to the Southern Indian Ocean Fisheries Agreement at p. 59 .

172 Convention on Cooperation in the Northwest Atlantic fisheries (Ottawa, 24 October 1978, in force 1 January 1979) 1135 UNTS 369 (Article I(h)). The consolidated version of this instrument, incorporating the 2017 amendments, is available online at https://www.nafo .int/Portals/o/PDFs/key-publications/NAFOConvention-2017.pdf.

173 Resolution 2/99 of 17 September 1999 to Guide Implementation of the Precautionary Approach within NAFO.

174 Indeed, the 2007 amendments were expressly intended to be applied 'in accordance with Article 6 of the 1995 [UN Fish Stocks] Agreement': Resolution 1/08 of 26 September 2008 on the Interpretation and Implementation of the Convention on Future Multilateral Cooperation in the Northwest Atlantic Fisheries.

175 See Wisz et al. (n 10) at p. 262 and Lam et al. (n 10) at pp. 348-349.

176 Available online at https://www.regjeringen.no/.../ud/.../declaration-on-arctic-fishe ries-16-july-2015.pdf (the 'Oslo Declaration'). For an extensive overview of this process 
although commercial fishing in these waters remains a distant and uncertain prospect, international obligations to cooperate in the conservation and management of marine living resources and to apply the precautionary approach necessitate the development of interim measures to deter unregulated fishing. To this end, the signatories pledged to ensure that 'any non-commercial fishing in this area does not undermine the purpose of the interim measures, is based on scientific advice and is monitored, and that data obtained through any such fishing is shared'.

The concept of 'non-commercial fishing' is not elaborated further in the Oslo Declaration, but appears most realistically confined to future exploratory and research activities. Indeed, this approach is reflective of policies pursued in areas within the national jurisdiction of particular signatories: commercial fishing has been precluded in Us Arctic waters since 2009, subject to an authorisation procedure requiring 'a fishery development analysis to ensure the best available science is used to move a species from unfished status to full fishery development,', ${ }^{177}$ as well as the Canadian portion of the Beaufort Sea

see EJ Molenaar, 'International Regulation of Central Arctic Ocean Fisheries' in MH Nordquist, JM Moore and R Long (eds), Challenges of the Changing Arctic: Continental Shelf, Navigation, and Fisheries (Brill, Leiden/Boston, 2016) 429-463, at pp. 448-457. The Oslo Declaration further stipulates that any commercial fishing shall be conducted solely under the auspices of 'one or more regional or subregional fisheries management organizations or arrangements that are or may be established to manage such fishing in accordance with recognized international standards'. This raises the intriguing question as to whether the Joint Norwegian-Russian Fisheries Commission, which manages shared and straddling stocks within the Barents Sea, qualifies as such and may therefore have a potential regulatory mandate with regard to, inter alia, new and exploratory fisheries within these waters. On the modern status of the Commission see I Dahl, 'Maritime Delimitation in the Arctic: Implications for Fisheries Jurisdiction and Cooperation in the Barents Sea' (2015) 30(1) International Journal of Marine and Coastal Law 120-157, at pp. 132-137 (suggesting that the Commission may meet the criteria enunciated by the UNFSA for an RFMA, if not necessarily that for an RFMO).

177 Fishery Management Plan for Fish Resources of the Arctic Management Area (available online at http://www.npfmc.org/arctic-fishery-management/) at p. 6 . This process shares elements of the CCAMLR data-collection regime, although it does not expressly utilize the procedures or terminology associated with new and exploratory fishing. These developments were contentious, however, because they also applied to the disputed segment of the Beaufort Sea between the us and Canada. Furthermore, the Canadian authorities viewed closure as being only one means of addressing sustainability risks, criticizing the decision not to consider, inter alia, exploratory fishing protocols for these waters: see further M Byers, International Law and the Arctic (Cambridge University Press, Cambridge, 2013) at pp. 180-181. 
since 2011, wherein a limited degree of exploratory fishing had previously occurred. ${ }^{178}$ In both instances, the national authorities envisage a precautionary approach to assess the status of potential target stocks and the ecosystem implications of future fisheries, prior to the contemplation of any prospective commercial fishing in these waters. ${ }^{179}$

Subsequent developments within the framework for a 'stepwise' approach as part of a 'Broader Process' towards the potential establishment of a new RFMO have involved extensive deliberations on the scope for 'non-commercial' fishing, with the initial signatories to the Oslo Declaration having been joined by China, Korea, Japan, Iceland and the EU in these negotiations. The European Parliament, for instance, has strongly advocated a precautionary approach to Arctic fisheries, repeatedly calling for a mechanism to generate reliable information concerning fish stocks and marine ecosystems prior to the contemplation of any expansion in fishing effort in a manner broadly analogous to the requirements of Article 6(6) of the UNFSA. ${ }^{180}$ Moreover, the Oslo Declaration expressly states that any eventual commercial fishing will be conducted 'in accordance with recognised international standards'. Although this term is also undefined in the text, it may be considered to have particular significance in

178 B Ayles, L Porta and RM Clarke, 'Development of an Integrated Fisheries Co-Management Framework for New and Emerging Commercial Fisheries in the Canadian Beaufort Sea' (2016) 72 Marine Policy 246-254, at p. 248.

179 For instance, licenses to fish for new or under-utilized species in Canada are addressed under the New Emerging Fisheries Policy, first adopted in 1996. Although weighted somewhat towards assessing the commercial viability of future stocks, feasibility and exploratory fishing licenses also involve limited fishing activities and the collection of ecosystem data. Similarly, in the Alaskan Arctic EEz, the us authorities have pre-emptively prohibited commercial fishing on all species other than Pacific salmon and Pacific halibut 'until sufficient information exists to authorize a sustainable fisheries management program': Fishery Management Plan for Fish Resources of the Arctic Management Area (n 177) at p. 6. The us has also staunchly opposed the introduction of commercial fisheries in the Arctic region until sufficient information exists to ascertain their impact upon stocks and the marine environment: see further R Barnes, 'International Regulation of Fisheries Management in Arctic Waters' (2011) 54 German Yearbook of International Law 193-230, at p. 225 .

180 See especially European Parliament Resolution of 22 January 2011 on a Sustainable EU Policy for the High North, para 22 and European Parliament Resolution of 12 March 2014 on an EU strategy for the Arctic, para 38. On the current position of the EU in this process see N Liu, 'The European Union's Potential Contribution to the Governance of High Seas Fisheries in the Central Arctic Ocean' in N Liu, EA Kirk and T Henriksen (eds), The European Union and the Arctic (Brill, Leiden/Boston, 2017) 275-295, at pp. 291-294. 
framing regulatory responses to new and exploratory fisheries that are likely to emerge within these waters in future years. ${ }^{181}$

Thus far, the models of best practice advanced under CCAMLR, in tandem with the standards for exploratory bottom-fishing outlined below, would appear to be the most plausible manifestations of current 'recognised international standards'. At the time of writing, full consensus on the oversight of exploratory fisheries in the central Arctic Ocean - which had initially proved elusive $^{182}$ - had recently been achieved. To this end, the negotiating parties were broadly aligned in considering that such activities should only be conducted pursuant to relevant conservation and management measures adopted by the meetings of the parties of any subsequent management body, in a manner similar to the regulation of exploratory fisheries by other RFMOs. Nevertheless, in keeping with the prevailing negotiating position that 'nothing is agreed until everything is agreed', the final details of this regime have yet to be formally approved. The participants in the 'Broader Process' are currently in the process of consolidating these points of consensus, with a view to articulating the final details of this regime in a text to be developed in future months. ${ }^{183}$

\section{Exploratory Deep-Sea Fishing and Vulnerable Marine Ecosystems on the High Seas}

As considered above, a general regime governing new and exploratory fisheries has been established under the UNFSA, a position inspired predominantly by the regulatory innovations of CCAMLR, and has been subsequently applied within a growing number of RFMOs. However, a second and more specific basis for the elaboration of overarching standards for such activities has emerged comparatively recently in the context of international efforts to protect the deep-sea environment from, inter alia, the poorly-controlled expansion of fishing effort. Since the mid-twentieth century, both commercial and exploratory

\footnotetext{
181 Molenaar ( $\mathrm{n} \mathrm{176)}$ at p. 455 .

182 Indeed, 'the manner in which the agreement addresses exploratory fishing' had been recently identified as an issue requiring further discussion: us Department of State, Chair's Report of the Meeting on High Seas Fisheries in the Central Arctic Ocean, 29 November1 December 2016, available online at http://thearcticjournal.com/press-releases/2733/ meeting-high-seas-fisheries-central-arctic-ocean.

183 us Department of State, Meeting on High Seas Fisheries in the Central Arctic Ocean, March 27, 2017: Chair's Report, available online at https://www.state.gov/e/oes/ocns/opa/ rls/269126.htm.
} 
fisheries have steadily progressed into offshore areas and deeper waters, as shallow-water stocks have become increasingly depleted and fishers have been accordingly forced to pursue alternative opportunities. ${ }^{184}$ Consequently, the mean depth of global fisheries has expanded four-fold since the mid-196os, ${ }^{185}$ accompanied by a steady proliferation of demersal fishing into areas beyond national jurisdiction.

Deep-sea fisheries have traditionally presented considerable regulatory challenges. In order to survive at advanced depths, in an environment characterised by cold temperatures, little light and limited productivity, such fishes typically exhibit delayed sexual maturity, slow growth and a high maximum age. In marked contrast to species exploited at shallower depths, deep-water species are thereby acutely vulnerable to the impacts of fishing, since with few exceptions such stocks can become rapidly depleted with little scope to regenerate swiftly. ${ }^{186}$ The risks of overfishing are compounded by a lack of baseline data concerning both deep-water stocks and their accompanying ecosystems, hence most deep-sea fisheries are considered unlikely to be either ecologically or economically sustainable in the long-term. Moreover, deep-sea fishing is considered to be especially destructive in comparison to other operations, given the predominant reliance upon the use of bottom-trawling, whereby heavily weighted nets are dragged across the seabed, presenting an amplified scope for benthic damage in the process. ${ }^{187}$

Notwithstanding these concerns, until the present century the pursuit of new deep-sea fishing opportunities was, in practice, largely unregulated. Indeed, by the time at which the UNFSA entered into force, there were significant portions of the global oceans - especially high seas areas - for which RFMOs had yet to be established, hence there were few pre-existing governance

184 T Morato, R Watson, TJ Pitcher and D Pauly, 'Fishing Down The Deep' (2006) 7(1) Fish and Fisheries 24-34, at p. 31.

185 EA Norse, S Brook, WWL Cheung, MR Clark, I Ekelund, R Froese, KM Gjerde, RL Haedrich, SS Hepple, T Morato, LE Morgan, D Pauly, R Sumaila and R Watson, 'Sustainability of Deep-Sea Fisheries' (2012) 36(2) Marine Policy 307-320, at p. 308.

186 Morato et al. (n. 184), at p. 25.

187 Bottom-trawling is an umbrella term for a variety of trawl fisheries, each of which uses gear variations that encapsulate weighted features with the capacity to impact both hard- and soft-bottom benthic ecosystems; see further JW Valdermansen, T Jørgensen and A Engås, Options to Mitigate Bottom Habitat Impact of Dragged Gears (FAO, Rome, 2007), at pp. $5^{-18}$. Accordingly, bottom fishing is widely understood as constituting any fishery that uses gear 'that either contact or are likely to contact the sea floor during the course of the fishing operation': A Bensch, M Gianni, D Gréboval, J Sanders and A Hjort, Worldwide Review of Bottom Fisheries in the High Seas (FAO, Rome, 2009) at p. 2. 
structures through which deep-sea fisheries might be addressed. Moreover, within the network of regulatory coverage that did exist, only four such bodies $^{188}$ were endowed with an express mandate to address deep-sea stocks, with many RFMOs having been established to address a single species, notably tuna or salmon. Compounding these regulatory lacunae, among the small collective of actors with an explicit remit to govern deep-sea stocks, it was legally questionable whether this competence extended beyond the management of the target stock to also include oversight of the wider ecosystem impacts of such fisheries. Indeed, as Molenaar observes, a strict interpretation of the existing mandates of these four bodies at the time would suggest that only CCAMLR retained express powers to regulate both deep-sea species and the ecosystem impacts of fishing upon them. ${ }^{189}$ Consequently, for most areas of the global oceans, deep-sea fisheries represented 'one of the last unregulated open-access frontiers, governed only by the general provisions of the UN Convention on the Law of the Sea.'190

Since the turn of the present century, however, endeavours to mitigate the prospective impacts of deep-sea fisheries - including those of an exploratory character - upon benthic ecosystems have been pursued primarily through the UNGA. In this regard, the UNGA has provided a convenient platform for the development of further standards, thereby overcoming two prominent regulatory concerns at the material time, namely the apparent absence of an obvious and readily identifiable forum for the consideration of deep-sea fisheries on the high seas ${ }^{191}$ and strong divergences of opinion as to whether deep-sea fishing in areas beyond national jurisdiction should be more appropriately

188 Namely CCAMLR, NEAFC, NAFO and the General Fisheries Commission for the Mediterranean (GFCM).

189 EJ Molenaar, 'Addressing Regulatory Gaps in High Seas Fisheries' (2005) 20(3) International Journal of Marine and Coastal Law 533-570, at p. 538.

190 KM Gjerde and D Freestone, 'Unfinished Business: Deep-Sea Fisheries and the Conservation of Marine Biodiversity Beyond National Jurisdiction' (2004) 19(3) International Journal of Marine and Coastal Law 209-222, at p. 209.

191 M Lodge, 'Improving International Governance in the Deep Sea' (2004) 19(3) International Journal of Marine and Coastal Law 299-316, at p. 301. For a full accounting of the variety of bodies through which efforts were made to promote deep-sea bottom fishing as an issue of regulatory concern, commencing in 2000 at the first meeting of the United Nations Informal Consultative Process on Oceans and the Law of the Sea, see LA Kimball, 'DeepSea Fisheries of the High Seas: The Management Impasse' (2004) 19(3) International Journal of Marine and Coastal Law 259-287, at pp. 263-272. 
addressed through binding or non-binding means. ${ }^{192}$ Accordingly, the political impetus of the UNGA has facilitated the subsequent emergence of a clearer degree of normative order to these activities, notwithstanding enduring definitional inconsistency between institutions as to the threshold of depth at which deep-water fisheries are considered to operate. ${ }^{193}$

In 2004, the UNGA first called upon states to act individually or through RFMOs to consider the prohibition of destructive fishing practices, including bottom-fishing, pending the adoption of appropriate 'conservation and management measures.' ${ }^{194} \mathrm{~A}$ further and highly influential Resolution requested states to 'identify vulnerable marine ecosystems and determine whether bottom fishing activities would cause significant adverse impacts to such ecosystems and the long-term sustainability of deep sea fish stocks, inter alia, by improving scientific research and data collection and sharing, and through new and exploratory fisheries'. ${ }^{195}$ Subsequent Resolutions have reinforced the protection of VMEs as a regulatory priority for RFMOs, ${ }^{196}$ which have been designated as the primary actors through which the operative paragraphs of Resolution 61/105 and subsequent instruments are to be implemented, alongside provision for the periodic review of progress under the auspices of the UN Secretary-General. ${ }^{197}$

192 See further DA Balton and DC Zbicz, 'Managing Deep-Sea Fisheries: Some Threshold Questions' (2004) 19(3) International Journal of Marine and Coastal Law 247-258, at pp. $25^{2-255}$.

193 In its global review of the scale and regulation of bottom fishing beyond national jurisdiction, the FAO examined those commencing at depths of over 200 metres, which, although not considered 'as a primary criterion,' may be considered an influential rule of thumb: Bensch, et al. (n 187) at p. 2. Nevertheless, as Oanta observes, the FAO's position has subsequently changed to a definition of 500 metres, while other actors have sought to classify particular species as deep-sea fishes, rather than specifying an arbitrary depth (n. 75), at pp. 592-593.

194 A/Res/59/25 of 17 November 2004, paras 66-69. This had been preceded in 2002 with a more ambiguous call for action by the UNGA 'to consider urgently ways to integrate and improve, on a scientific basis, the management of risks to marine biodiversity of seamounts and certain other underwater features within the framework of the [1982 Law of the Sea] Convention': A/Res/57/141 of 12 December 2002, para 56. Resolution 59/25 stopped short of instituting a full ban on such gear, which had been advocated by a vociferous lobby of states and NGOs: Takei (n 146) at p. 112.

$195 \mathrm{~A} /$ Res/61/105 of 8 December 2006, para 83(b) (emphasis added).

196 A/Res/64/72 of 4 December 2009, paras 113, 117 and 119-124; A/Res/66/68 of 6 December 2011, paras 121, 126, 129, 130, 132, 133 and 134; A/Res/71/123 of 7 December 2016, paras 174-182.

197 Resolution 64/72 (para 128) and Resolution 66/68 (para 137). 
In 2009, the FAO adopted the International Guidelines for the Management of Deep-Sea Fisheries in the High Seas, which were developed to assist RFMos in the implementation of the various commitments established under paragraphs $76-95$ of UNGA Resolution 61/105, which included provision for new and exploratory bottom fisheries. The FAO Deep-Sea Fisheries Guidelines established that deep-sea fisheries are to be 'rigorously managed' during the experimental, exploratory and established stages of their development. ${ }^{198}$ Although the parameters of these stages were not expressly defined by the FAO, a broadly analogous position to Article 6(6) of the UNFSA has been advanced, with states encouraged to ensure that 'conservation and management measures for [deepsea fisheries] should ensure that, while knowledge is low, harvest rates are kept low enough to minimise risk to sustainability and harvests only increase as knowledge, management capacity and [monitoring, control and surveillance] increase.' ${ }^{199}$ Accordingly, RFMOs should elaborate appropriate mechanisms for reviewing assessments, determinations and management measures, including the receipt of advice from appropriate scientific bodies and the consideration of effective mitigation measures. ${ }^{200}$ Such procedures should also be supported by international observer programmes, for which

[h]igher levels of coverage are required, in particular for experimental and exploratory stages of a fishery's development', especially where such fishing takes place outside an RFMO, which should continue 'until measures in place to manage these fisheries and prevent significant adverse impacts are evaluated and determined to be effective. ${ }^{201}$

The Guidelines also considered an 'appropriate set of rules and regulations' to be a core element of a 'functioning regulatory framework' for the opening of such areas to exploratory fisheries, which should include regulations to protect vulnerable populations, communities and habitats. ${ }^{202}$ Precautionary conservation and management measures, including catch and effort controls, were considered 'essential' during the exploratory phase of a deep-sea fishery and should include measures to manage the impact of the fishery on low-productivity species, non-target species and sensitive habitat features. ${ }^{203}$ To this end,

\begin{tabular}{ll}
\hline 198 & Para 23. \\
199 & Ibid. \\
200 & Para 50. \\
201 & Para 55. \\
202 & Para 61. \\
203 & Para 65.
\end{tabular}


the FAO recommended the institution of precautionary effort limits, in the absence of reliable estimates of sustainable catches of both target and non-target species, supported by precautionary measures to prevent serial depletion of low productivity stocks. This approach was also to be supported by the regular review of stock status and a downwards revision of catch estimates if appropriate, alongside measures to prevent significant adverse impacts on VMEs and the comprehensive monitoring of all fishing effort, catch statistics and interactions with VMEs.

In a manner reminiscent of the further implementation of Article 6(6) of the UNFSA, the position on VMEs advanced under UNGA Resolution 61/105, in conjunction with the FAO Deep-Sea Fisheries Guidelines, has strongly influenced the formulation of common regulatory standards for deep-sea fishing. As intended by the UNGA Resolutions, particular RFMOs have subsequently developed clear policies and procedures to regulate exploratory fishing in the specific context of the deep-sea environment. In this regard, a broadly uniform framework for the management of prospective deep-sea exploratory fishing has been adopted by a growing array of RFMOS, maintaining a clear emphasis on prior approval and the scientific review of intended exploratory activities, alongside targeted data-collection requirements and the graduated expansion of fishing effort in a restrained and precautionary manner.

This broad approach is clearly exemplified by the arrangements adopted by NEAFC, wherein the proactive management of deep-sea ecosystems dates back to 2004. ${ }^{204}$ In 2008, NEAFC adopted an Interim Exploratory Bottom Fishing Protocol for New Bottom Fishing Areas, ${ }^{205}$ Under these arrangements the Commission, in consultation with the International Council on Exploration of the Sea (ICES), has mapped the parameters of bottom fishing undertaken within the NEAFC Regulatory Area to date, with such areas maintained in an Annex to the Recommendation which establishes a definitive, yet adjustable, list of existing fishing areas. Exploratory bottom fishing is thus defined as 'all commercial bottom fishing activities outside area closures and existing bottom fishing areas, or if there are significant changes to the conduct and technology of bottom fishing activities within existing bottom fishing areas.' ${ }^{206}$

204 At this juncture, the NEAFC parties interpreted the Commission's competence in a broad manner to close a series of deep-sea sites to bottom-trawling: see further Molenaar (n 189) at pp. $53^{8-}-539$.

205 Recommendation XVI:2008.

206 Article 2(d), Recommendation 9:2015; see Consolidated Text of all NEAFC Recommendations on Regulating Bottom Fishing, available online at www.neafc.org. 
Any prospective expansion of bottom fishing beyond existing sites is addressed under Articles 6 and 7 of the NEAFC Bottom Fishing Recommendation, which places the onus on the proposing party to gather data to present to the Commission. Under Article 6, a Notice of Intent (NoI) must be submitted to the Commission at least 6 months prior to the purported fishing activities and, in a manner broadly similar to the CCAMLR framework for new and exploratory fisheries, will include a harvesting plan, a mitigation plan and a 'sufficient system' to record data. NoIs are subject to prior review and approval by the parties and the Permanent Committee on Management and Science (PECMAS), with preference to be given to 'exploratory bottom fishing using fishing gear and methods with the least bottom contact, in well-mapped areas and at times when impacts are likely to have the least adverse impacts on organisms other than the target species.'. ${ }^{207}$ The Commission is to review the reports and may decide to authorise bottom fishing in these areas as 'existing bottom fishing areas' based on the results of exploratory bottom fishing conducted in the previous two years. ${ }^{208}$

This process operates in conjunction with Article 7 , under which the parties must submit a preliminary assessment of known and anticipated impacts of the proposed bottom fishing activities, to be conducted in the light of advice from ICES or, if none is available, 'to the best of the ability of the Contracting Party concerned'. ${ }^{209}$ PECMAS undertakes an evaluation of the documentation 'in accordance with the precautionary approach,' taking account of risks of significant adverse impacts upon VMEs before advising whether the proposal should be approved and whether particular mitigation measures should be adopted.

Given the considerable overlap in membership and the contemporaneous formulation of their respective policies, SEAFO has adopted a near-identical approach to that of NEAFC. In 2009, CM 17/09 on bottom-trawling was introduced as an interim conservation measure to address the demands of Resolution $61 / 105$, which was subsequently revised and reformulated as CM 29/14 on bottom fishing activities and vMEs in the SEAFo Convention Area. Under this provision, exploratory bottom fishing is defined in a similar manner to that of NEAFC as 'all commercial bottom fishing activities outside area closures and existing bottom fishing areas, or fisheries within existing bottom fishing areas when a new fishing method and/or strategies are attempted to

\footnotetext{
207 Article 6(5)

208 Article 6(8).

209 Article $7(2)$.
} 
be used. ${ }^{210}$ As with NEAFC, a NoI is required with materially the same criteria and subject to prior scientific assessment, with a view towards identifying the current scale of bottom fishing in the Convention Area. This process was completed in 2011 and, in 2015, a first deep-sea exploratory fishery was initiated by Japan for Patagonian toothfish. ${ }^{211}$

A similar procedure is also envisaged in the context of the $\mathrm{NAFO}$, which has also collated this data to identify a series of Seamount, Coral and Sponge Protection Zones, within which bottom fishing is prohibited for particular periods of time. ${ }^{212}$ Nevertheless, some initial interpretive difficulties were experienced under the auspices of NAFO, whereby an arbitrary allocation of $20 \%$ of closed seamounts remained open to exploratory fishing, contingent upon the fulfilment of these approval processes, until all bottom fishing in these areas was prohibited in 2012. ${ }^{213}$ The NFPC has also adopted a similar approach, having established an Exploratory Fishery Protocol for these waters that requires the prior approval of separate plans for harvesting, mitigation, catch monitoring and data collection. ${ }^{214}$

Meanwhile, CCAMLR first expressly considered the problems raised by bottom trawling in 2006, at which point it was determined that any future proposals to conduct such activities in high seas locations of the CAMLR Convention Area would need to be notified in accordance with its procedure for new fisheries. ${ }^{215}$ At this juncture, CMS 21-01 and 21-02 were revised so that future notifications with bottom-trawl gear would be required to provide information concerning known and anticipated impacts on VMEs, and specific CMs have been adopted to restrict and regulate bottom fishing in the CAMLR Convention Area. ${ }^{216}$ As with the position with CCAMLR exploratory fisheries generally, bottom fishing requirements have been most successfully implemented in the Ross Sea, having led to the identification of a series of VMEs in recent years. ${ }^{217}$

\footnotetext{
210 Article 2(d).

211 Report of the Tenth Meeting of the Scientific Committee to SEAFO, para 6.9.2.

212 NAFO Conservation and Management Measures, Article 16.

213 See further D Diz, 'The Seamounts of the Sargasso Sea: Adequately Protected?' (2016) 31(2) International Journal of Marine and Coastal Law 359-370, at pp. 362-363.

214 CMM 2016-05: Bottom Fisheries and Protection of Vulnerable Marine Ecosystems in the Northeast Pacific Ocean and смм 2016-06: Bottom Fisheries and Protection of Vulnerable Marine Ecosystems in the North-western Pacific Ocean; both measures entered into force on 16 January 2017.

$215 C C A M L R-X X V(\mathrm{n} \mathrm{62})$, para 12.18.

216 See especially CM 22-06: Bottom Fishing in the Convention Area.

217 CCAMLR-XXXII (n 110), para 5.67.
} 
SPRFMO has also adopted a broadly similar set of policies, which expressly apply 'in addition to the requirements in any other measures adopted under Article 22 of the Convention with respect to new and exploratory fisheries'.218 Under СмM 4.03, participants are to establish their bottom fishing footprint (i.e., 'a map of the spatial extent and distribution of historical bottom fishing in the Convention Area of all vessels flagged to a particular Member or CNCP [Cooperating Non-Contracting Party] over the period 1 January 2002 to $3^{1}$ December $\left.2006^{\prime}\right)^{219}$ and restrict fishing activities to these parameters. In 2012 a Bottom Fishery Impact Assessment Standard (BFIAS) was introduced, under which participants are required to prepare a new bottom fishery impact assessment if a substantial change in the fishery has occurred, which would render it likely that the risk or impacts of the fishery may have also changed. ${ }^{220}$ The BFIAS mandates a description of the proposed fishing activities, a full impact assessment, information on the stocks to be fished and adherence to the FAO Deep-Sea Fisheries Guidelines. This procedure has already engendered a promising degree of good practice, with the extensive assessments conducted by New Zealand and Australia pledging particular attention to the risk of gear loss, additional training for observers and fishers and the development of an industry-wide code of practice. ${ }^{221}$

Buttressing these general policies - and reflective of its proactive regulatory ethos - SPRFMO has adopted a more expansive interpretation of bottom fishing, which also incorporates mid-water trawling on seamounts, given the propensity for some degree of contact with seabed features even at this comparatively more elevated depth. ${ }^{222}$ This position thereby potentially catches a wider array of fishing activities within the rules governing exploratory fishing. To date, this approach remains a striking exception to more general RFMO practice, although similar policies were considered by NAFO in 2015, which failed to

218 This was first established under CMM 2.03 (Management of Bottom Fishing in the SPRFMO Convention Area; 2014), para 21; subsequently replaced with CMM 4.03 (Management of Bottom Fishing in the SPRFMo Convention Area; 2016). Unlike other RFMOs, the SPRFMO requirements apply to all bottom fishing activities, not simply exploratory endeavours: see further R Barnes, 'The Proposed LOSC Implementation Agreement on Areas Beyond National Jurisdiction and its Impact on International Fisheries Law' (2016) 31(4) International Journal of Marine and Coastal Law 583-619, at pp. 613-614.

219 Para 6.

220 Bottom Fishery Impact Assessment Standard; available online at https://www.sprfmo .int/conservation-measures/benthic-impact-assessments/, at p. 5 .

221 See further the full series of documentation available online at https://www.sprfmo.int/ conservation-measures/benthic-impact-assessments/.

222 Report of the Second Scientific Committee Meeting, at p. 15. 
find consensus on the issue but instead imposed particular restrictions on the design and deployment of mid-water trawl gear. ${ }^{223}$

The policies adopted by a range of RFMOs to date are eminently suggestive of an emerging trend towards the regulation of deep-sea fishing, with particular reference to exploratory endeavours. This position is reinforced by the express designation by the UNGA of RFMOs ${ }^{224}$ as the conduit through which deepsea fishing in areas beyond national jurisdiction is to be regulated, in conjunction with the technical guidance developed for these particular fisheries by the FAO in order to implement the operative paragraphs of Resolution 61/105 and subsequent instruments. Although the UNGA does not regularly impose a political imperative towards a course of regulatory action for specific fishing activities, the isolated examples of previous measures indicate that such Resolutions have nevertheless proved to be a compelling stimulus to RFMOs and other actors. ${ }^{225}$

223 Diz (n 213) at pp. 366-367.

224 As Takei observes, the position of actors other than RFMOs is somewhat uncertain in this respect, because '[n] either UNGA Resolutions nor the FAO Guidelines explicitly articulate the potential role of coastal states with regard to deep-sea fisheries on the high seas above the continental shelf' (n 146) at p. 133. This has resulted in a general degree of reluctance towards taking unilateral action, although one intriguing exception remains the position of the EU. In this regard, in seeking to implement the pertinent UNGA Resolutions, the EU has confined the activities of its Member States in the deep-sea context in areas for which no RFMO has been established or interim measures have not yet been agreed for the protection of VMEs: see Council Regulation (EC) No 735/2008 of 15 July 2008 on the protection of vulnerable marine ecosystems in the high seas from the adverse impacts of bottom fishing gears [2008] Official Journal L201/8. Under this provision, the use of bottom gear is prohibited in areas 'where no proper scientific assessment has been carried out and made available': Article 6(1).

225 This is particularly true of restrictions mandated by the UNGA upon the use of large-scale pelagic driftnets on the high seas, which rapidly gained a significant degree of regulatory traction to the point at which commentators have suggested that these standards now represent customary international law: see further GJ Hewison, 'The Legally Binding Nature of the Moratorium on Large-Scale High Seas Driftnet Fishing' (1994) 25(4) Journal of Maritime Law and Commerce 557-579. On the elaboration of these provisions see DR Rothwell, 'The General Assembly Ban on Driftnet Fishing' in D. Shelton (ed) Commitment and Compliance: The Role of Non-Binding Norms in the International Legal System (Oxford University Press, Oxford, 2003) 121-145, at pp. 126-131 and R Caddell, 'Caught in the Net: Driftnet Fishing Restrictions and the European Court of Justice' (2010) 22(2) Journal of Environmental Law 301-314, at pp. 301-304. Nevertheless, the use of the UNGA as a more politically charged 'bully pulpit' to promote developments in international fisheries management - especially in driving adjustments to technical measures has been strongly criticized in other quarters: see WT Burke, M Freeburg and EL Miles, 
In the present context, particular commitments towards deep-sea fishing may be identified, with RFMOs and their participants charged with definitively mapping the extent of existing fishing activities, with any proposed expansion deemed to be exploratory in nature. Although the extension of a fishing footprint is not inherently precluded, it is subject to prior consent based on precautionary scientific review and, as with the CCAMLR approach to new and exploratory fisheries, clear requirements as to the collection of specified further data. Although exploratory bottom fishing remains comparatively limited - both in terms of its physical scope and its emphasis on potential impacts upon particular benthic features - this approach provides for the concerted acquisition of baseline data to better evaluate appropriate fishing locations in a manner somewhat reminiscent of more traditional forms of environmental assessment. ${ }^{226}$ This marked uniformity in approach indicates that a number of RFMOs have applied this broad template in order to implement the commitments articulated within the relevant UNGA instruments, for which these requirements may thereby be considered to be representative of a recognised set of minimum standards for deep-sea exploratory fishing in areas beyond national jurisdiction.

\section{Conclusions}

The international regulation of fisheries has long been predicated upon essentially static fishing grounds and their continued ability to provide sufficient yields in the face of rising demand and increased participation. However, current projections indicate profound impending changes to the distribution of many commercially and nutritionally significant stocks and, in turn, the future location and composition of catches. The prospective displacement of fish and fishing effort towards new stocks, locations, depths and techniques poses substantial governance challenges. Previously un(der)-fished stocks and their accompanying ecosystems are acutely vulnerable to anthropogenic excesses. All too often, new fisheries have been pursued with a cavalier disregard for scientific uncertainty, duly inflicting significant damage upon target stocks and

'United Nations Resolutions on Driftnet Fishing: An Unsustainable Precedent for High Seas and Coastal Fisheries Management' (1994) 25(2) Ocean Development and International Law 127-186, at p.137.

226 G Sander, 'International Legal Obligations for Environmental Impact Assessment and Strategic Environmental Assessment in the Arctic Ocean' (2016) 31(1) International Journal of Marine and Coastal Law 88-119, at pp. 105-106. 
the wider marine environment before meaningful and considered regulation can be applied. Despite this rather chequered history, new fisheries conversely provide an inviting opportunity - frequently absent from more established enterprises - to secure a culture of proactive and ecologically sensitive management $a b$ initio. The regulation of new and exploratory fisheries thereby represents an intriguing test-case for the application of the precautionary approach to international fisheries management.

New and exploratory fisheries are subject to a hitherto unheralded and unexplored regulatory framework, which can be seen to have developed in two distinct regulatory contexts. Having initially emerged as an issue of niche concern within the Southern Ocean, far-sighted regulatory developments within CCAMLR influenced the contemporaneous elaboration of the UNFSA. The resulting provision, Article 6(6), establishes that new and exploratory fisheries should be subject to cautious conservation and management measures, which are to remain in place pending the acquisition of sufficient data to ascertain the prospective environmental impacts of continued fishing, so as to facilitate well-informed management decisions concerning the further development of a particular fishery. Although Article 6(6) remains somewhat ambiguous, its symbolic importance should not be underestimated, having prompted the regulation of new and exploratory fisheries to be included to at least some degree within the mandates of all post-UNFSA RFMOs, some of which - notably SPRFMO - have subsequently developed comprehensive standards for such activities in a relatively truncated timeframe.

Latterly, a similar degree of global influence has been forthcoming in respect of policies to address the protection of VMEs from deep-sea fisheries on the high seas, as expressly mandated by the UNGA, with a growing number of RFMOs having since established targeted procedures for exploratory fishing at advanced depths in areas beyond national jurisdiction. The explicit designation by the UNGA of RFMOs as the regulatory actors through which such commitments are intended to be addressed, and the subsequent striking uniformity in the implementation of these commitments, are also compellingly suggestive of the formation of recognised international standards for the pursuit of these specific fishing activities.

These developments notwithstanding, the maturation of policies towards new and exploratory fisheries has thus far only occurred under the auspices of CCAMLR. The development of a proactive management framework for new and exploratory fisheries within the Southern Ocean has been rightly lauded as a significant regulatory achievement, for which CCAMLR has established a series of procedures to ensure that such fishing is subject to prior approval based on the capacity and previous conduct of the operator, and remains within clearly 
prescribed limits, with entitlements contingent upon the assiduous collection of pertinent data. In principle, these requirements represent a notable practical application of the precautionary approach, allowing for fisheries to be developed in an informed, controlled and responsible manner, with scope for adjustments in catch limits, gear usage, data-collection requirements and fishing areas if necessary. This regulatory template has already been successfully exported into neighbouring SPRFMO and would represent an effective model for consideration by other bodies, including any resultant RFMO for the central Arctic Ocean - within which exploratory fishing may be considered likely to commence in future years - that may arise from the current 'Broader Process'.

However, if the regulatory arrangements for new and exploratory fisheries under CCMALR are effective in design, complications have been experienced in their implementation. There has been a steady blurring of the requirements and ethos for new and exploratory fisheries with other forms of research fishing, which may generate future interpretive difficulties within and beyond CCAMLR. More significantly, although compliance with CCAMLR measures has been generally high, difficulties have arisen in securing sufficient data from these activities. This has resulted in an uneven knowledge base between the CCAMLR exploratory fisheries, yielding a high concentration of data from particular endeavours, whereas lesser information has been consistently returned from others. Combined with an operational bias towards collecting data that is commercially valuable, a number of CCAMLR exploratory fisheries have thus operated as de facto commercial fisheries. This position arguably fails to meet the central precautionary objective of these activities. Indeed, as particular CCAMLR Members have themselves warned, 'exploratory fisheries are just that, exploratory, and should not be assumed to be precautionary if they continue for many years without satisfactory research., ${ }^{227}$

Ultimately, new and exploratory fisheries represent a distinct conceptual challenge to the precautionary approach itself: such activities primarily occur in dynamic marine ecosystems and under hostile research conditions, thus full scientific certainty is unlikely ever to be attained - yet the legal framework envisages a transition to commercial management upon the receipt of an agreed volume of requested information. Critics of the CCAMLR approach to new and exploratory fisheries have argued that the present arrangements have neither demonstrated sufficient adaptability nor fully addressed reasonable scientific uncertainties. Conversely, there is strong endorsement within influential advisory quarters that the requirements of $\mathrm{CM}$ 21-02 have been met for particular initiatives. If CCAMLR's Ross Sea Exploratory Fishery is a reliable barometer

227 CCAMLR-XXIX (n 87), para 12.36. 
of regulatory intent, exploratory fisheries in commercial transition are likely to be subject to additional and ongoing research requirements absent from fully managed fisheries. This approach may accordingly represent the most pragmatic solution to the uneasy compromise inherent in the pursuit of new fisheries resources in the face of enduring uncertainty. 